Article

\title{
Framework and Methodology for Establishing Port-City Policies Based on Real-Time Composite Indicators and IoT: A Practical Use-Case
}

\author{
Ignacio Lacalle *, Andreu Belsa, Rafael Vaño and Carlos E. Palau \\ Departamento de Comunicaciones, Universitat Politècnica de València, 46022 Valencia, Spain; \\ anbelpel@upv.es (A.B.); ravagar2@upv.es (R.V.); cpalau@dcom.upv.es (C.E.P.) \\ * Correspondence: iglaub@upv.es
}

Received: 2 July 2020; Accepted: 20 July 2020; Published: 24 July 2020

check for updates

\begin{abstract}
During the past few decades, the combination of flourishing maritime commerce and urban population increases has made port-cities face several challenges. Smart Port-Cities of the future will take advantage of the newest IoT technologies to tackle those challenges in a joint fashion from both the city and port side. A specific matter of interest in this work is how to obtain reliable, measurable indicators to establish port-city policies for mutual benefit. This paper proposes an IoT-based software framework, accompanied with a methodology for defining, calculating, and predicting composite indicators that represent real-world phenomena in the context of a Smart Port-City. This paper envisions, develops, and deploys the framework on a real use-case as a practice experiment. The experiment consists of deploying a composite index for monitoring traffic congestion at the port-city interface in Thessaloniki (Greece). Results were aligned with the expectations, validated through nine scenarios, concluding with delivery of a useful tool for interested actors at Smart Port-Cities to work over and build policies upon.
\end{abstract}

Keywords: Smart Port-Cities; composite indicator; real-time; Internet of Things; traffic congestion; framework and methodology

\section{Introduction}

Traditionally, port and cities have been working as independent siloes, striving separately to reach innovation goals towards better sustainability and economic growth. During the past few decades, the increasing pace of urban population growth [1] and expansion of maritime commerce [2] have brought forth environmental and societal challenges which affect both sides. In light of new wave technologies that are already having an impact on port-cities, the moment to tackle joint challenges making use of the most advanced innovations towards the future Smart Port-Cities is now [3]. Looking only at the big numbers, there are 33 megacities in the world (with more than 10 million inhabitants) [4]; 25 of them are port-cities, accumulating more than $25 \%$ of global container trade volume [5]. Naturally then, useful solutions addressing Smart Port-City challenges will be a key game changer from both business and societal perspective in the forthcoming years. This is the context in which this work is framed.

A Smart Port-City is, by definition, the combination of a Smart City with a Smart Port. The notion dates back to the SmartPORT initiative proposed by Hamburg in 2012 [6]. However, the concept goes far beyond that. A Smart Port-City entails the integration of information from the two domains in a transparent manner and the realization that port-city actions must be envisaged as a holistic entity taking advantage of the era of massive data [7]. One of the main challenges of Smart Port-Cities is the establishment of effective policies between the Port Authorities (and relevant agents) and the 
Municipality or Regional Governments [3]. Agreeing upon security, mobility, energy and environmental matters appears crucial for the future of port cities. Those policies should lead to a more efficient and productive mutually beneficial relationship between the involved entities. According to the Association Internationale Villes et Ports (AIVP) Agenda 2030 for Sustainable Port-Cities [8], "port cities are the best scenarios to test innovative solutions tackling different issues". AIVP went farther in the list, and clearly defined 10 sustainable goals: climate change, energy transition, sustainable mobility, renewed governance, port culture and identity, port-city interface, health and life quality and protecting biodiversity.

Among the former, a huge concern for citizens, municipalities, and all kinds of organisations (Non-Governmental Organizations-NGOs-included) are those related with vehicle traffic [9] and its effects, which are directly related to climate change. Nowadays, the vast majority of urban vehicles are still powered by non-degradable, highly-polluting fossil fuels [10], with a series of hazardous consequences to the ecosystem and its inhabitants [11]. There is a growing trend to establish norms and policies seeking to reduce the pollution levels at cities; either supported by legislation [12] or just initiatives for improving both traffic congestion and the well-being levels of citizens [13]. Linking with the goal of this work, this effect is even more noticeable in port-cities, where the fact of hosting a port in the immediate surroundings of living neighborhoods entails its own hindrances (e.g., [14]). While business efficiency may drive operational and technical innovations, sometimes supported by Information and Communications Technology-ICT [15], sustainability is also a true stakeholder value for port authorities. Achieving sustainability goals for a port, such as by reducing its emissions or being more transparent on port-city relations can provide a long-term payback. Despite being difficult to measure, this payback can yield immaterial gains such as increased residential citizens' acceptance of port operations, which would be an ideal pillar to build policies upon. There are documented examples of ports striving through numerous initiatives and investments to raise awareness and improve citizen acceptability [16]. However, today, there are no consolidated indicators to demonstrate to the citizens the strong commitment of port authorities, to reduce the environmental impacts and other potential burdens of their activities. The most relevant reference is the Global Reporting Initiative-GRI-guidelines for sustainability, which does not even have seaport-sector-specific guidelines [17].

Taking advantage of Internet of Things-IoT-techniques and real-time features opens a wide range of options for defining port-cities policies such as enabling decision-making after analysing traffic congestion at specific spots in cities. Allowing the different actors in the port-city relation to measure, analyse and act based on solid, formal, reliable indicators will enable, for instance, setting specific thresholds on the traffic volumes, establishing alarms and alerts over certain ranges, accounting for responsibilities during specific events, proposing alternative mobility solutions or simply checking the evolution throughout time for tackling further actions.

The port-city interface is normally modelled as a single convergence point having the following features: demographics, urban development, public tender procurement, traffic, noise, pollution, employment and sustainability. To drive towards sustainable benefits over that interface, it is worthwhile to follow the principles indicated in the "Sustainable Cities" report by the European Commission [18], which indicates that clear quantified indicators must be used for that purpose. Not only are indicators powerful for measuring progress and performance in specific areas; according to the Policy Influence for Indicators-POINT—study [19], those indicators have a huge potential to drive the creation of policies. To use them as tools for defining policies, indicators must be both quantifiable and measurable. Additionally, the construction of those indicators must be a joint activity of both municipality/regional authorities and the port itself. Co-design of the methodology, significance, relevance, and boundaries of each indicator is a challenging task that must be faced in a joint fashion.

The indicators will be, sometimes, rather simple (e.g., the number of jobs generated by the port). In contrast, more often those indices will be complex due to the influence of different parameters (e.g., the environmental pollution from the port or the traffic increase attributable to port activities). In this work, the authors propose to use composite indicators with that purpose. According to the 
European Commission, composite indicators are ideal for situations where different parts of an event representation have no common meaningful unit of measurement and there is no obvious way of weighting them to have a single illustrative value [20]. This definition fits perfectly the usual case on Smart Port-Cities interface points. The rationale behind that usage will be to come up with composite indicators to be used to advocate desirable policies, ensuring that the process of construction is transparent, and it has clear backing statistical conceptual principles.

The paper's objectives can then be summarized as follows:

(1) To explore how to translate the knowledge of the field of composite indicators to the port-city interface.

(2) To define how to build solid indicators with that purpose, focusing on their calculation and prediction to represent real-world phenomena in the context of a Smart Port-City

(3) To analyse the various technological options to construct an architecture leveraging IoT techniques covering the indicator implementation.

(4) To propose an IoT-based software framework accompanied with a methodology for its co-design and deployment on a real use-case.

(5) To effectively conduct a small scale experiment consisting of implementing a composite indicator use-case reflecting the traffic congestion in the interface between the port and the city of Thessaloniki (Greece).

Underlying those objectives, there appears a hypothesis aim to be validated: "IoT can be used for deploying solid, robust services for assisting the decision-making on setting port-city policies".

The framework developed has been applied and deployed in a real Smart Port-City (Thessaloniki), thus providing a legitimate testbed. Additionally, the work in this paper has usability potential as an IoT solution for mission-critical infrastructures of the Smart City, as the port and its interface with the city can be considered as such [21]. Besides, the work has advanced in the definition of semantic modeling of city knowledge, specifically in the traffic congestion realm. Finally, one of the last objectives of this work is to apply time-series forecasting over traffic and city data, clearly seeking to extract knowledge using machine learning (ML). In particular, it focuses on both understanding phenomena from historic data and catering to short-term prediction decisions using real-time data.

The reminder of the article is organized as follows: Section 2 presents the state-of-the-art and relevant previous work. Section 3 explains thoroughly the proposed framework and its methodology to be applied in a use-case, which is presented as well. Section 4 shows the results of applying the framework to a real traffic congestion scenario. Section 5 briefly discusses the knowledge to be extracted from the results and its utility. Last, Section 6 concludes the article with some suggestions on future work directions.

\section{Related Work}

\subsection{Open Data in Smart Ports and Smart Cities}

Open data is a key element in the relationship between the Smart Cities and Smart Ports. Reference [22] describes open data initiatives as part of the efforts by governments to provide transparency, better empower citizens, foster innovation, and reform public services by investigating the impacts of open data innovation on different Smart City domains like the economy, education, energy, the environment, governance, tourism, transport and mobility. Reference [23] explains that open data is not only global data collected and opened by the government, but also includes data shared among individual citizens and industries with the government and public. Related with this paper experiment's domain, reference [24] analyses the current and future situation of open data in Smart Ports. It summarises the benefits of using open data for enabling typical applications in the port operations (e.g., truck gate appointments, vessel calls data management, yard operation scheduling or hazardous material tracking within the port premises), helping coordinate port operations to deal 
with unexpected delays caused by city issues like traffic congestion and a fluid exchange information between the port community and the port vicinity. However, a reluctancy of ports to release certain data to the community (researchers, other stakeholders) was also observed, especially those that concern business model operations or private protected data.

Nowadays, the main world cities provide their own open data platforms. For example, the European Data Portal has analysed the status and features of Open Data portals in eight of the largest capital cities [25] in Europe and in medium-sized European cities [26] like Thessaloniki. The information from these portals is useful for the ports, as it is originated by sensors connected to the surrounding areas providing flow of information between the entire city, the port neighborhood, and the port. The analysis, use and processing of this data is leading to the advent of applications and services improving the daily activities of the port and their impact on the environment.

\subsection{Interoperability at Middleware Level of Heterogeneous Data in a City}

From an architectural point of view, a study of the current status of functionalities, components and platforms to achieve IoT interoperability that can be used in a Smart Port City solution was performed.

Some research projects focused on achieving interoperability between IoT platforms provide a detailed state of the art overview of the architecture of existing IoT platforms. The INTER-IoT [27] study is based on a layered classification approach regardless of the application domains. This project covered the whole IoT architecture to achieve a complete interoperability solution including devices and platforms. The ACTIVAGE project [28] study is closely related with middleware platforms and is based on a layered classification: device level, connectivity level, cloud level and application level; providing a complete picture of the features and functionalities of the main IoT platforms. After reviewing the literature, the main research needs on that regard for completing this paper are data access from several heterogeneous data sources and open data and the middleware interoperability.

Related to access to the data sources, ref. [29] presents a city-wide IoT data management layer providing some Representational State Transfer-REST—and linked Open Data Application Programming Interfaces-APIs- that collect and show data related to elderly people. That work highlights the need of defining a common format to integrate the data, allowing one to define different levels of data abstraction, scalable infrastructure, and semantic meaning to the stored information. Reference [30] explains an ontology for semantic interoperability and linked data integration. The FIWARE project [31] proposes some data models [32] to enable data portability for different applications highlighting their potential for Smart City solutions. Regarding middleware interoperability, some available open source technologies like Apache Kafka [33] provide real-time processing of IoT events, while some works (e.g., [30]) depict "the sensor middleware" as a main element that collects, filters, and combines data streams from virtual sensors or physical devices. In addition to solutions like Kafka, that approach ensures proper semantic annotations of the data collected. FIWARE provides the ORION Context Broker [34], a component to manage the entire lifecycle of context information in a common format.

Focusing on middleware-level implementations for Smart Cities in the literature, ref. [35] performs an exhaustive analysis of the international organizations involved in Smart City standardisation. It presents a complete study about Smart City vendors and their software systems. It starts by exposing the two barriers to Smart City solutions. First, the current Smart City technologies are based on non- interoperable custom systems that are not replicable in other cities. Second, the architectural design efforts have not yet converged to a clear reference, creating uncertainly among stakeholders. It compares 47 different Smart City software systems based in their domain work, communication protocols, training and promotion resources, location of deployments and open software design and architecture. It emphasizes the importance of the methodology to choose a Smart City software architecture system. Reference [36] lists some platforms and solutions from a design and architectural point of view classifying them by their requirement analysis, challenges achieved and reference architecture and comparing them based in the following components: IoT middleware, data repository, 
data processing, stream processing, cluster management, cloud environment, data access, security, and machine learning. Ref. [35] shows that the FIWARE Platform covers all the main domains expected in Smart City solutions. FIWARE is an open system that offers a public API and is compatible with main communication protocols which has been successfully deployed, for example in some cities in Spain and Argentina. In addition, it is used in some research projects. Reference [37] explains the main components of FIWARE platform and offers a light application to illustrate the usage of the FIWARE platform to build rich applications for smart cities. The FIWARE community [38] envisages an attempt of an official approach to a Smart City solution with the aim of providing added value from the data handled by the context broker. Finally, Ref. [39] does a performance evaluation of FIWARE based on smart cities' needs. It indicates that the use of FIWARE as a core element can rely on a basic configuration for low load levels, but in the case of high load levels deploying an appropriate shared cluster to be used as global data storage facility is recommended. That work used the official FIWARE agents to access to the data from heterogeneous data sources. In addition, it is worth explaining that the implementation of IoT agents and connectors between data sources and middleware layer need to be improved to support the load of current and future large-scale scenarios for IoT. To improve this flaw, the current work by FIWARE developers is targeting the creation of its own methodology and implementation of the agents to improve the platform performance. The FIWARE platform has been selected to form the device and middleware level component of the architecture presented in this paper and it has been customised to adapt it to Smart Port-City expectations.

\subsection{Top-Layer Services for Smart Port-Cities Based on IoT}

The basis of IoT technologies are heterogeneous, measurable, understandable, and interconnected objects. Their implementation in cities and communities provides applications and services for Smart Cities. Reference [40] provides several definitions of the smart cities concept and an analysis of the evolution of smart cities-related research. Reference [41] identifies the components of a smart city and related aspects of urban life, the key dimensions of a smart city, a list of indicators for smart cities assessment in some rating systems and examples of initiatives. The study in [40] is done from an Information Systems perspective and is focused on number of aspects of smart cities: smart mobility, smart living, smart environment, smart citizens, smart government, and smart architecture, as well as related technologies and concepts. However, not all technological services in cities can be rendered to a "smart city" concept [42]. According to [43], only those that make extensive use of IoT, advanced communication networks and enable user-device interaction can be considered attributable to this concept. The smart city approach has been now widely adopted by cities worldwide as well as via research activities. In [42], several significant examples of top-layer services in smart cities are explained. Spain stands out in smart city real deployments, especially in Barcelona [44] and Santander [45].

Northern-Europe countries have been focused on energy through the AIM [46] and IntUBE [47] projects and on air pollution management through GreenIoT [23]. Internationally, IBM launched a series of deployments creating ad hoc private company units for smart city projects, especially in America [48], while China has embarked on an ambitious initiative throughout the whole country to strengthen city management and to improve city services and functions [49]. Among the previous, the most frequent initiatives are those focused on smart civil infrastructure, air pollution, demographics, smart urban mobility, and smart energy.

There is a smaller volume of literature focusing on the application of top-layer services to smart ports and smart port-cities. The work in [50] explains that, to some extent, the smart port concept can be considered a subset of the smart city. It provides examples of successful implementation of those technologies in relevant ports, indicating that they can improve the port terminal performance, customer satisfaction or reduce the environmental impact. Reference [51] lists a considerable number of smart port initiatives, some smart ports term explanations and a classification of a smart port's activity domains and subdomains. It consists of four main activity domains: operations, environment, 
energy, and safety and security, which are, in general, pretty aligned with the smart city concerns exposed in Figure $1 b$.

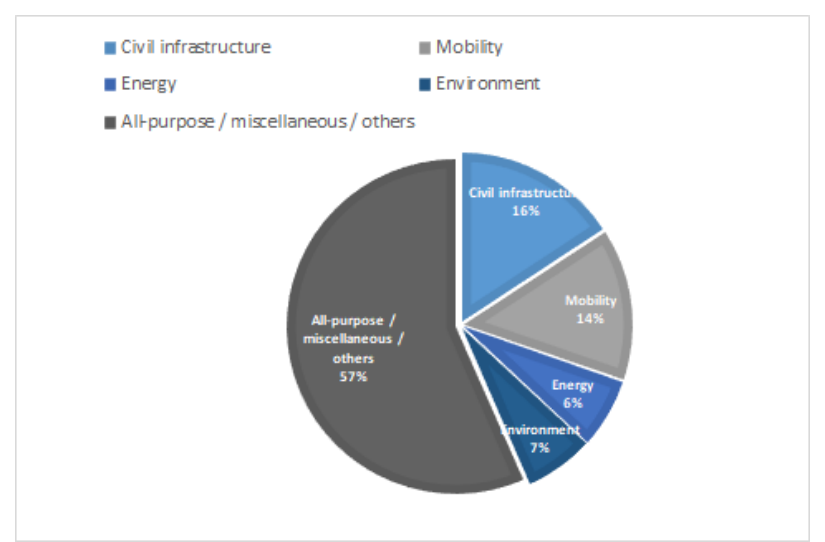

(a)

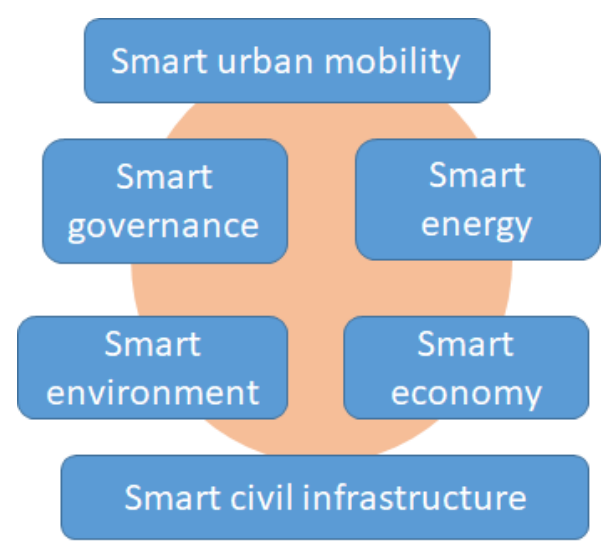

(b)

Figure 1. Smart Cities services analyses 2010-2018. Data extracted from the study done in [42]: (a) percentage of appearance in papers; (b) main areas of interest for deploying Smart City services.

There have been some trials to establish a formal classification of top-layer services for smart cities (we have clarified that smart port-cities are a subset of the latter. For the paper, authors decided to use the taxonomy proposed in [52]. This classification was chosen because it enables the combination of smart services dealing with more than one smart city dimension, which is aligned with the hypothesis of our work. For example, persistent high traffic congestion or other transportation/mobility services produce harmful emissions to the atmosphere $\left(\mathrm{NOx}, \mathrm{CO}_{2}\right.$, PMs, etc.) while affecting the local life quality, shaping the perception from the citizenry and potential future civil infrastructure investments and demographic evolution. Some of the former (public safety or demographics) deal with smart living and smart governance. Therefore, a classification system considering multidimensional spots of one smart service was preferred compared to a single tag division. The taxonomy selected drills down every smart city service under three categories, following the so-named "DMS" schema, where "D" stands for data, " $\mathrm{M}$ " refers to analytic methods and " $\mathrm{S}$ " encodes the service description.

Following that taxonomy, the work in this paper can be properly framed in a "traffic, weather and port-activities" data (D), "co-design and implementation of a composite indicator" (M) and "interpretation of real-time and predicted values" (S).

\subsection{Real-Time Composite Indicators in Smart Port-Cities}

A composite indicator $(\mathrm{CI})$ relies on a mathematical combination of individual indicators that represent different dimensions of a concept. The main objective of this work is to design a system leveraging the IoT data and techniques to represent a complex phenomenon using composite indicators.

Some advantages of using a CI are ease of interpretation, facilitation of rankings, appropriateness for acknowledging evolution through time, provision of big picture and benchmarking suitability. On the other side of the coin, CIs may send misleading messages if not interpreted properly, may entail loss of information, may deviate focus on relevant dimensions and requires high quantity and quality levels of the data to be used to populate all sub-indicators [53,54]. However, if properly tackled and analysed, it can be a paramount keystone for future smart port-city policies, according to the authors.

The usage of CIs has long tradition in some sectors, especially in measuring country performances [55]. However, there is a trend on an increasing use of the composite index methodologyfirst detailed and explained by the European Commission (EC) in 2002 [20]—for representing interesting indicators in other realms. Some examples were found focusing on land use type and ecosystem services in urban contexts [56], on environmental sustainability (e.g., the Environmental Sustainability 
Index proposed by the World Economic Forum (WEF) [57] or the Port Environmental Index of the PIXEL project [58]), in the urban economy (e.g., Internal Market Index by DGMARKT [59] or Economic Sentiment Indicator by the EC [60]), on societal aspects (the Human Development Index published by the United Nations [61]) and in science, technology and information advances (e.g., Technology Achievement Index by the United Nations [62] or the ICT index proposed by Fagerberg [63]).

Regarding a technical implementation of a CI analytic software, the main reference found is enclosed in an initiative from the EC-funded Joint Research Centre (JRC) together with the Organisation for Economic Co-operation and Development (OECD) published in the "Handbook on Constructing Composite Indicators" [64]. This publication provides a complete methodology and user guide to the construction and use of composite indicators. While there are several types of composite indicators, the handbook focuses only on those which compare and rank country performance. This is out of scope of our research but provides a clear view of the composite indicator topic related with constructing a composite indicator and explaining a toolbox for constructors. Some years a European Commission's Competence Centre on composite indicators and scoreboards (COIN) was launched the COIN Tool, a MS Excel-based software tool to help develop and analyse composite indicators and scoreboards. It provides guidelines on how to develop methodologies to construct robust composite indicators. As previously, the tool was focused on rankings, but it is a clear example of digitising the process of creating and managing a composite index and its results. It is interesting how they apply the formulas of their methodology using MS Excel formulae and interaction interface. Nevertheless, COIN does not process data in real time or take advantage of IoT platforms.

Narrowing down the research scope, another interesting project targeting composite indicators appeared. The CITYkeys project (EU-funded) [65] is focused on discovering and implementing CIs for smart cities. A huge set of actionable indicators were defined in this project, including cyber-security, local food production, healthy lifestyle, ground floor usage, among others; clearly observing the relevant intervening actors, different examples of deployment and thorough descriptions [66]. However, the calculation was mostly based on Likert evaluations, suing very simplistic scorings (e.g., [67]) and static data coming from reporting or literature databases. Although a performance system was proposed [68], the work in CITYkeys was assumed as incomplete for the purpose of this paper. Another implementation analysed by the authors was the "Dashboard thinking cities" promoted by Telefónica using FIWARE commodities in all the procedure [69]. This option was carefully studied considering that: (i) it uses FIWARE Context Broker (ORION) and (ii) other components that were considered to be included in this paper, (iii) it enables a KPI-powered module explicitly designed to create "Key Performance Indicators" (KPIs) for smart cities and (iv) it allows a multi-dimensional multi-service approach built upon open data and open-source technologies. However, it was discarded as there was not found any relevant real application of the concept, seeming for the moment an interesting proposal pending to be validated in practical cases. Besides, it did not consider including options for tailoring the structure of the CI or interacting with prediction options.

The specific experiment of this paper tackles a traffic congestion use-case. Measuring traffic congestion in a systematic way has proved to be useful. As an example, in [70] a congestion use-case in a real port in China was optimised using a predictive algorithm. In this regard, using composite indicators has already been explored in [71], in which a e composite index-Traffic Congestability Value (TCV) — was defined to monitor the congestion by measuring in real-time number of vehicles and average while driving through specific land areas on the East of India.

Finally, fine-tuning the research looking for validated CIs in smart ports, the most relevant work revealed in the state of the art is [51]. There, a Smart Port Index is proposed to allow ports improve their resilience and sustainability. However, in this development, the joint perspective from the city was not included. Besides, the usability was formulated to inter-port comparison and the KPIs values were extracted over literature references and not supported by an IoT-based system. 
The previous analysis confirmed authors' perception that there is not an ad hoc framework and methodology that both smart ports and smart cities can rely on to build useful composite indicators in real time.

\subsection{Machine Learning for Traffic Congestion Forecasting}

Although not part of the main hypothesis of the work, the authors explored the state of the art of predictive models to forecast traffic and traffic congestion. In particular, this matter is framed within the supervised timeseries modelling, which is a discipline within machine learning.

Few consolidated tools have been found on relation of road traffic prediction for port-cities. The most relevant proprietary solutions are AIMSUN [72], PTV Vissim [73] and IBM traffic prediction tool [74], which has been successful in port-cities in Singapore. Regarding open tools, Veins [75] is the most referenced and used, in a field that stands out for tailored and customised approaches.

About the machine learning models used, there has been an evolution since the "beginning" of this field of study, which date back to 40 years ago [76]. The most used techniques in modern approaches are neural and Bayesian networks, fuzzy and evolutionary techniques, applied to specific application environments with different accuracy outcomes [77].

The expectations on this paper are to replicate some of the already-validated models and methods of the literature and have them applied to a real composite indicator use-case. The objective is not to advance the state of the art on this field, but rather to find a way to merge these technologies with a real-time framework based on IoT concepts.

\section{Materials and Methods}

\subsection{Framework}

The core of this work consisted of the design and implementation of a technological framework to calculate and represent a smart port-city composite indicator (CI). The construction of the software pillars of the framework was driven by the authors taking advantage of the advances of the research project PIXEL [78]. The authors are active participants in that project, which has the aim to develop an IoT-based platform enabling the interoperable interconnection of data sources in ports towards operations and environmental impact optimisation.

The intention of the proposed framework is to properly process raw data to become actionable information in composite index format. To round out the complete system, the framework is escorted by a methodology for its deployment and usage (see Section 3.4).

For the scope of this paper, using the results of previous research [79] has allowed the authors to end up with a solid basis to deploy the framework. Some reference architectures leveraged were RAMI4.0 [80] and IIRA [81], which provide a consolidated layered-approach for IoT service-oriented implementation for practical deployments in a mixture of Industries. The essence was adopted, while specific additions and tailoring were necessary. Drawing from the heart architecture of PIXEL, the framework designed to validate our hypothesis makes use of certain components, altogether with some custom modules and carefully selected extensions. Figure 2 depicts the architecture's modular composition.

With the vision of delivering an actionable, practical, simplified IoT architecture for enabling composite indicators calculation in smart port-cities, a set of mandatory elements were to be included. First, from the IoT-technical perspective, there was the need to collect and pre-process the data. Afterwards, it needs to be semantically annotated to be interoperable and used by the upper layers. Visualisation and storage are also required (at least, on a bare minimum expression) on every IoT-service system [82]. Second, according to the nature of the service to be provided (see taxonomy in Section 2.3), a series of modules must be embedded; (i) forecasting values of the indicator, (ii) long-term storage for training predictive models and for statistical analysis, (iii) execution of the CI computation and (iv) intelligence to orchestrate the data and process flow. Moreover, the authors made the strategic 
choice of relying on micro-services and containerization for service provision in order to facilitate development and deployment [83].

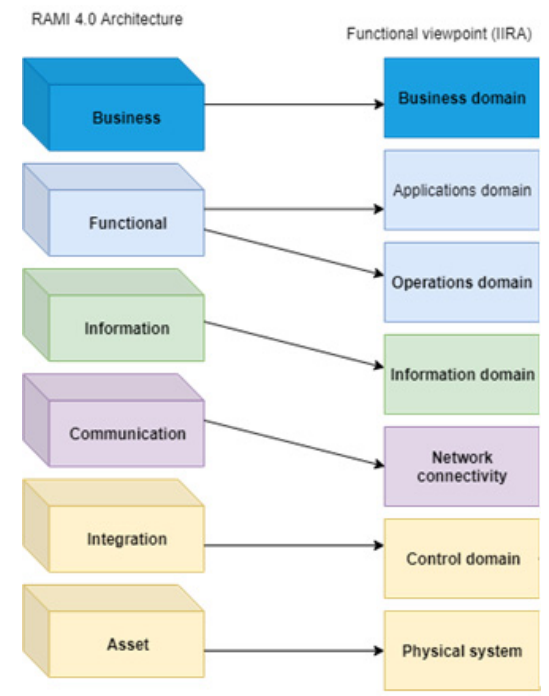

(a)

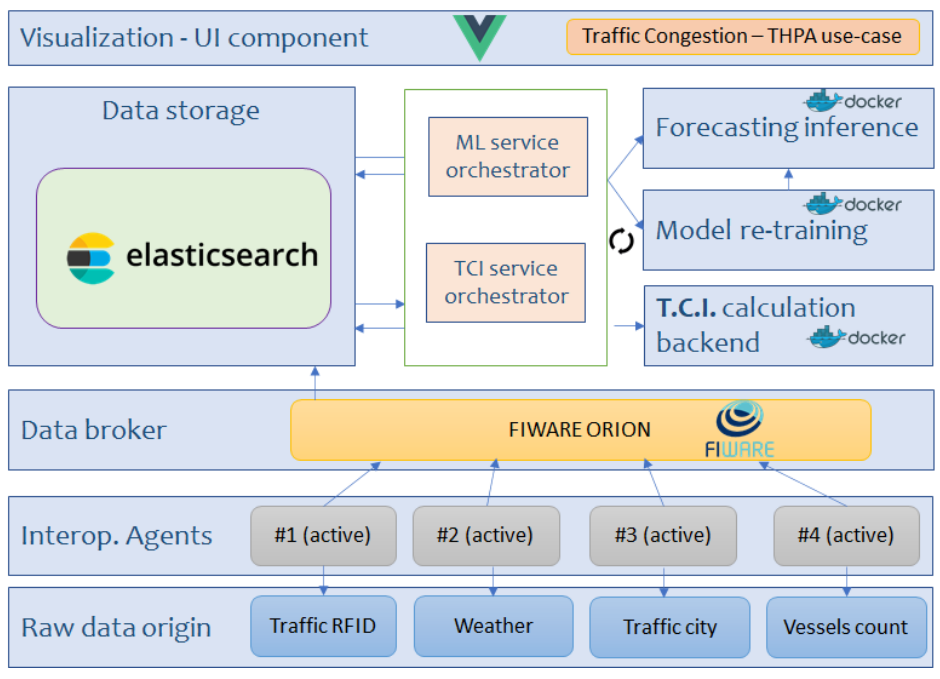

(b)

Figure 2. Architecture of the proposed framework: (a) IoT layered reference architecture RAMI4.0 and IIRA-image extracted from [79]; (b) Modules and technologies of the framework. The figures are aligned to reflect the mapping reference layer - component.

All the previous considerations, added to other requirements summarized in Table 1 led the authors to propose the architecture depicted in Figure 2b. Besides, the rest of this section aims at describing succinctly the main function of each module, the technologies selected and the development details for this work.

Table 1. Technical and functional requirements for designed the IoT framework of this paper.

\begin{tabular}{clc}
\hline Requirement & Type ${ }^{\mathbf{1}}$ & Coverage by Module \\
\hline Short- and long-term storage of the data & Technical & Data storage \\
Automatic scheduled execution & Technical & Orchestrator \\
Flexibility for filtering, selecting the data & Technical & Data storage \\
Semantic interoperability and common syntax & Technical & Data Broker, agents \\
Agile integration and deployment & Technical & Containerisation \\
To be able to add new data sources & Functional & Data Broker, agents \\
To train a predictive model and use it for inferring CI & Functional & Training, inference \\
To setup the weights and methods to calculate the CI & Functional & CI, orchestrator, UI \\
To visualise the current value of the indicator (real-time) & Usability & UI - User interface \\
To visualise the evolution of the indicator during a day & Usability & UI \\
To visualise the predicted evolution of the indicator & Usability & UI, training, inference \\
To make the framework as configurable as possible & Usability & UI \\
\hline
\end{tabular}

${ }^{1}$ Here, authors did not consider exploitability and non-functional requirements, neither used specific tools or methodologies to come up with the table above. Requirements were extracted from authors' previous experiences and from concerns witnessed by contact with close port-city stakeholders.

\subsubsection{Data Broker Module}

This is a classic IoT component with the crystal-clear mission of gathering into a centric element all the "entities" that provide data to the framework. A crucial concept in this module is the "data format consistency". Here, the design in this work was to work under uniformed syntactic and semantic structures for all data sources incoming. Hence, an additional processing element must be incorporated (interoperability agent) to make raw data comply with the expected schema. Authors have prepared the framework (and encourage all future users) to use standardised interfaces to communicate this 
module southbound and northbound. Taking advantage of the use of the open-source reference for IoT solutions, all data formats in this experiment have been designed to follow FIWARE NGSI data models [32]. For the implementation of this module, the project PIXEL was the main reference. While the Data Broker module selected technology is FIWARE ORION [34], the interoperability agents are not mandatory to be implemented with a closed specific technology. Recommendation from authors is to use the pyngsi Python framework provided by PIXEL project [84]. The selection of ORION brings an IoT flavor to the whole framework, guaranteeing the real-timeness of the system thanks to the publish-subscription approach. Instantiation of this module and agents in the experiment of this paper is explain in Section 3.4.1.

\subsubsection{Data Storage Module}

The goal of this module is to guarantee persistence of the data feeding the composite indicator. The most significant conditions to be met by this module were high availability, containerisation, open-source, and low-resources consumption. Instead of opting for complex implementations of data storage modules such as PIXEL Information Hub [85], Apache Hive [86] or the classic relational databases like MySQL [87] or MariaDB [88], the choice for this work was Elasticsearch [89]. This selection was preferred over simpler technologies such as MongoDB [90] due to Elasticsearch's comprehensive data flattening, easy-to-use programming interface and automated filtering capabilities.

\subsubsection{Orchestration Module}

This acts as the orchestrator providing the intelligence to the procedure. As commented, one of the decisions was to deliver the backend modules (CI calculation and prediction) as "independent" containerised services. This module is in charge of coordinating the process to rhythmically execute those services, indicating which data must them be fed with and other variables coming from user preferences. Some options were discussed for the implementation, such as Node-RED [91], Docker Swarm [92], Kubernetes [93] or PIXEL's Operational Tools [94]. However, as the application for Smart Port-City composite indicators proved to be straightforward from a service layer point of view, the authors decided to design this module in the framework as a combination of Docker compose [95] instructions and Linux bash scripts scheduled using cron.

\subsubsection{Visualization Module}

The options for visualizing composite indicators are motley. Ranging from direct-databaseconnection tools such as Kibana [96] or Grafana [97] for simple inspection to a fully customized layout, the state of the art is plenty of opportunities. Drawing from the requirements in Table 1, the election had to be customizable enough to allow the authors build their own visualizations and configuration forms. Therefore, based on the baseline approach tackled by PIXEL project, the framework Vue.js (JavaScript) [98], was selected. On that regard, the authors developed a set of tailored tabs with dynamic graphs to represent the information associated to a CI utility. Details on the application to this experiment can be found in Section 3.4.4.

\subsubsection{Dual Computing Approach}

While the majority of the previous modules are functional enablers, carrying out mandatory tasks for the correct execution of the service, the core calculations to extract valuable knowledge out of the data are still to be revealed. Authors have designed the framework to have two clearly differentiated "data processing spots", as it can be seen in Figure 3. In a simplified way, raw data comes from the left block in, it is converted into a common agreed format through the interoperability agents, it is stored and then it is retrieved from the CI mathematical backend calculations to obtain the final single metric. 


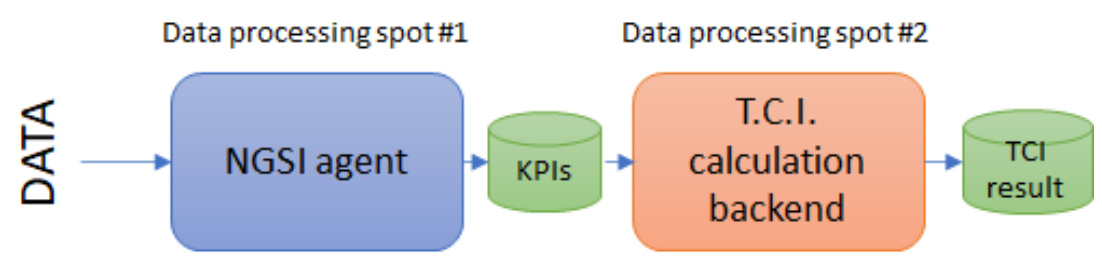

Figure 3. Dual computing approach followed for the proposed framework.

This structure was decided by authors to allow flexibility to change/correct/adapt/add further data sources in a constrained part of the architecture, without affecting the structure of the whole framework, leaving the calculation from input data to the composite indicator (and subindices) as a fixed code not supposed to be changing throughout the time. Additionally, this way, the most burdening computation could be jointly borne by different equipment.

(1) Data processing spot \#1: KPIs computation block

Following the rationale behind one of the tools created in PIXEL, the Port Environmental Index (PEI) [99], the authors decided to address the CI calculation from a cascade down-top indicator flow. Henceforth, for this work, it was adopted the approach of considering each piece of data input as one KPI (Key Performance Indicator) to be monitored, constituting one leaf piece of the indicators tree.

This block constitutes the basis of the CI calculation, aiming at converting data into actionable KPIs and make them ready to use is what the agents perform. NGSI prefix is used to explicitly state FIWARE compliance. It is worth to mention that the NGSI agents' development is an action that will deviate from one "Smart Port-City composite index" use-case to another. As data will be different, the treatment at this level will vary and it will be needed a careful, tailored analysis to handle the development of the agents. The functions that all NGSI agents must provide are the following:

- To retrieve the data from the original source: the framework has been designed to accept a two-fold connection mode: (a) the agent actively queries the data source origin following a periodic pattern. This option will apply whenever the data is behind a reachable API; or (b) the agent includes an embedded data broker so that the active origin can publish on it. This case is usually present in the cases where built-in IoT stations or smart sensors are used.

- To process the data and convert it to KPIs: this development will be different for each data source, becoming the most craftsmanship development when a composite indicator tool wishes to be deployed using our framework. It might range from a simple format conversion to a complex data relation, combination, and construction. Additionally, each NGSI agent may have different number of inputs and outputs. Despite the fact that the usual case (see Section 3.4.1) is to realise a 1:1 relation, the framework has been prepared to accept $1: \mathrm{N}, \mathrm{N}: 1$ and $\mathrm{N}: \mathrm{N}$ setups as well.

- To update the entity in the Data Broker: The main goal of the agent is to make data reach the information layer of the IoT stack of our framework. Hence, the KPIs obtained are submitted to the Data Broker (ORION) via a PUT HTTP-Hyper Text Transfer Protocol—message in order to update the "KPI entity". The format selected has been to extend one of the FIWARE Data Models: KeyPerformanceIndicator [100]. More details can be found in Appendix A.

(2) Data processing spot \#2: Composite Index calculation and prediction block

This block consists of a series of calculations that will be invariant, following a clear algorithm. These calculations are transparent for the actors intervening in the composite index definition and usage, remaining as a "black box" that takes some inputs, processes them, and provides an output (result of the execution). According to the designed framework methodology (see Figure 4), this processing spot performs a non-serialised 6-step mathematical operation procedure: 


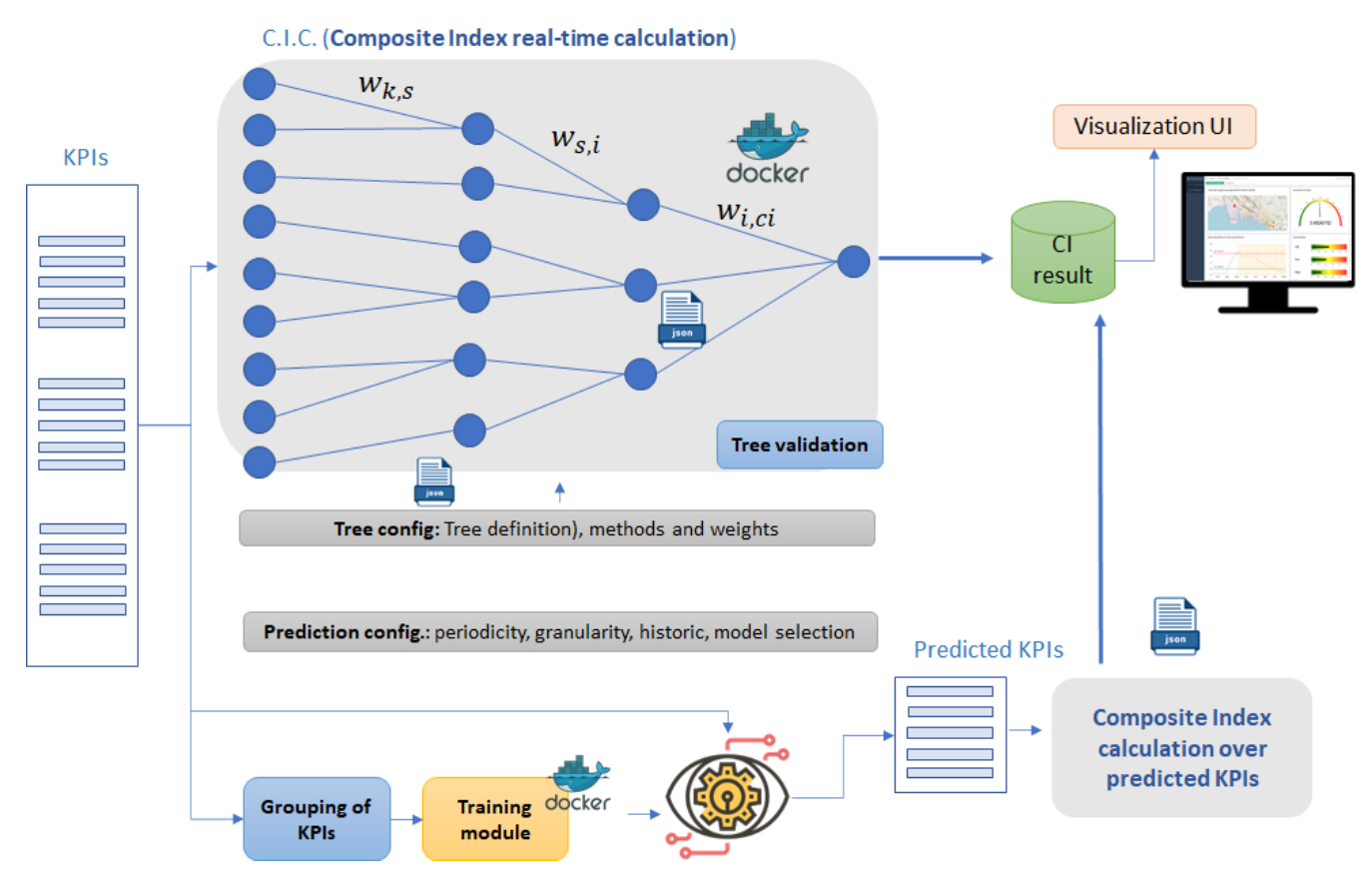

Figure 4. Composite Index calculation and prediction block.

(1) To configure the CI inputs, the structure of the tree and the associated parameters, such as aggregation methods, normalization methods and weighting values through a developed visual interface. See Section 3.4.4. to discover the utilization of this component.

(2) According to the parameter set in (1), including the scheduling, the periodic calculation of the index. First, the KPI values are properly normalised (crucial step on a CI procedure). Then, starting by the leaf node, a cascading algorithm including aggregation, weighting and combination leads towards a final index value. Technologically, this component has been developed as a dockerised (packaged in a Docker container [101]) standalone Java application.

(3) To configure the predictive component of the framework by the user, specifying batch sizes, periodicities and model to be used for the inference of KPIs.

(4) According to (3), the training module groups the KPIs stored, fits again the pre-trained model selected, updates it, and makes it ready to be used. Technically, this module has been developed as a dockerised Python script.

(5) To apply the prediction over predicted KPIs. This module has also been developed as dockerised Python script.

(6) To visualise the results of both real-time calculation of the composite index (2) and the observation of the predicted evolution of the composite indicator via a specific dynamic graph (5).

\subsection{Proposed Use Case}

The experiment conducted in this paper consist of envisioning, designing, implementing, and testing an IoT-powered composite indicator reflecting the traffic congestion in the interface between the port and the city of Thessaloniki in Greece.

The Port of Thessaloniki is spotted very close to the city center, which has been throughout the years built around the economic opportunities that a port brings. During the last ten years, a huge number of diverse activities have been transferred to the surrounding area of the port, which has been increasingly selected as the ideal place to establish office-based businesses. Several luxury hotels and new business centers, including brand-new and re-modelled buildings have been constructed just outside the port area, thus being directly influenced by normal daily port activities. Establishing a physical base near to the port may have certain disadvantages, such as the noise or the (possible) 
impact of dust in the air. However, there are also pluses, such as the views offered to customers and employers and the privilege of direct contact with the business heart of the city.

For what directly concerns this work, in the selected use-case setup (Figure 5), the aforementioned port activities and growing businesses are hugely impacting the traffic congestion in the surrounding streets to the port and city center. Moreover, the industrial area of Thessaloniki, the main bus station and logistic centers are all located at the west side of the city. The main truck gate of the Port is on its west side resulting in a significant amount of traffic during the peak hours. Here, peak hour is determined by the truck movements (entries and exits of the port), which curve is similar to Figure A4a) (in Appendix B). The context explains what makes the area already environmentally burdened.

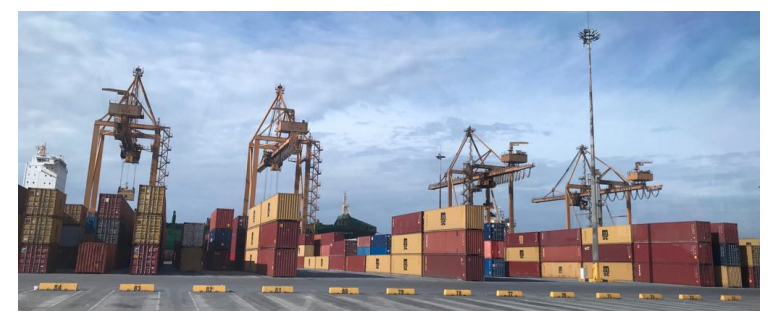

(a)

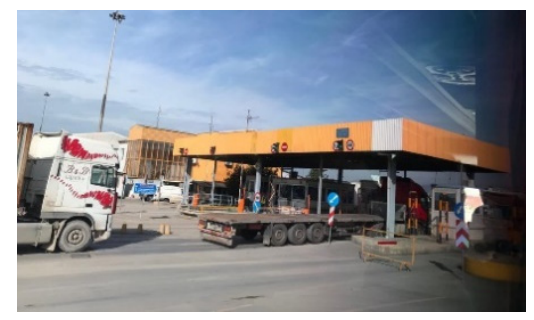

(b)

Figure 5. Setup of the use-case. Port-City of Thessaloniki and its interface. (a) Picture of cranes of the ports' container terminal; (b) One of the truck gates of the port.

The objective of the use-case is to demonstrate the hypothesis proposed by using the framework outlined in Section 3.1 towards allowing a port-city to build policies upon a legit, reliable, real-time based composite indicator.

According to the previous, the event that is wished to be modelled is the traffic congestion at the interface of the port with the city. The composite index defined is, therefore, a Traffic Congestion Index (TCI). The TCI must consider the different elements intervening (in a per-day assumption), as well as the different actors that are involved in the policies definition.

On the one hand, the traffic congestion level is represented by the number of vehicles at the gates of the port (real port-city interface). However, there are other factors influencing the congestion level, such as port activities (e.g., by the number of ships being operated), the weather conditions (e.g., by affecting port operations decreasing productivity [102] or noticing that rainfall leads to more traffic congestion in cities [103]), the seasonality (season, month, day within the week) and, naturally, the contribution for the city itself, i.e., traffic on the port surroundings attributable to the city. Higher number and of more complex nature requirements could be argued to be considered [104], but for the scope of this work, the main factors affecting the congestion were the previous.

On the other hand, the main actors involved in the traffic congestion event to tackle with the TCI are the port authority, the city municipality and, indirectly, the citizens of Thessaloniki. During the work exposed in this paper, an active participation was received from the port authority, funneled via the participation in the PIXEL project. The Port Authority of Thessaloniki (THPA) collaborated within that project by providing traffic data at the gates of the port, by co-designing the concept of the experiment (possible influences in the traffic, relevant data sources to explore), by indicating a series of functional requirements and by outlining the visualization layout that a port authority would like to have in that kind of experiment. With regards to public participation, the authors did not have close enough contact with the local community nor resources to involve, in this case, citizens, the municipality or other entities into the experiment. As this use-case is aimed to serve as a starting point-proof of concept-, this was finally deemed not mandatory thus not included in the methodology of the experiment. However, to bring their perspective into the experiment, authors designed the system flexible enough to allow the introduction of new parameters at any moment. 
Additionally, this intervention has been also properly considered within the methodology (see steps 1 and 2 of the methodology in Section 3.4).

The experiment draws from historic and real-time data (see Section 3.3), deploying a number of IoT techniques (see Section 3.4) leveraging the framework developed (see Section 3.1), ending with the visualization (see Section 4) and interpretation of results (see Section 5). The paper does not aim to go beyond in the effective implementation of policies in the city of Thessaloniki. However, according to the authors, the work carried out might clearly be used for that purpose.

For replication of a smart port-city composite index experiment, and for clarifying the use-case composition, Table 2 illustrates the main features and characteristics. The framework exposed might cover a wide range of use-cases, which could be represented using the proposed format.

Table 2. Representation of a smart port-city composite index use-case.

\begin{tabular}{cccc}
\hline Event to Model & Actor Intervening & Relevant Data & Further Usage of Index \\
\hline & Port Authority & $\begin{array}{l}\text { - Traffic at the gates of the port } \\
\text { - Vessels berthed at the port }\end{array}$ & $\begin{array}{l}\text { Internal process- and } \\
\text { relationship-centric practices, } \\
\text { leading to less traffic and pollution. }\end{array}$ \\
$\begin{array}{c}\text { Traffic congestion at the } \\
\begin{array}{c}\text { interface of the port with } \\
\text { the city-TCI }\end{array}\end{array}$ & $\begin{array}{c}\text { City Municipality } \\
\text { Public/citizens }\end{array}$ & $\begin{array}{l}\text { - Traffic in the city } \\
\text { - Weather in the city }\end{array}$ & $\begin{array}{l}\text { Monitoring and auditing. } \\
\text { Knowledge and port acceptance. }\end{array}$ \\
\hline
\end{tabular}

\subsection{Data}

The experiment has been run with a series of raw data coming from diverse sources. In this section, we aim at describing the historic and real-time data used, as well as the pre-processing made to store and utilise it properly.

\subsubsection{Traffic at the Gates of the Port Using Radio-Frequency Identification—RFID—Sensors}

The baseline data for the experiment comes from two RFID sensors placed at the gates of the port of Thessaloniki, as depicted in Figure 6. The gates are 10A and 16 (as numbered by the port) and are equipped with RFID-based sensors allowing them to identify and catalogue all vehicles entering and exiting the port.

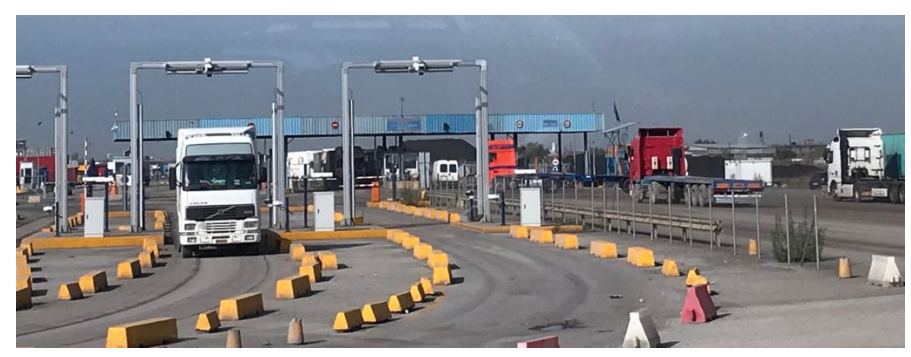

(a)

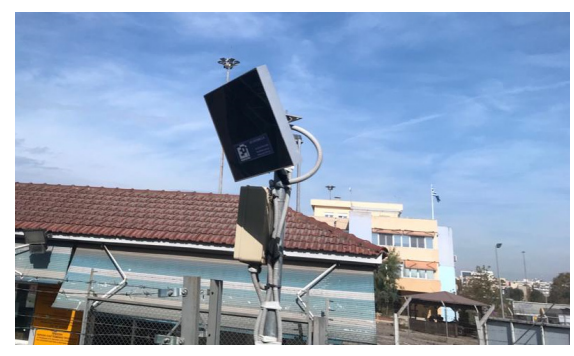

(b)

Figure 6. Data coming from RFID sensors in the gates of the Port of Thessaloniki: (a) RFID arcs at the entrance to the port of the trucks gate (16); (b) RFID tag and vehicle detection plate at the common-vehicles gate (10A).

The data has been provided to the authors of the paper under the collaboration with the Thessaloniki Port Authority, S.A. (THPA) framed within the PIXEL research project. This data has been granted by THPA and served by its IT department via a web API created explicitly for the mentioned project. Internally, the data is managed by a Port Community System.

Historical data from April 2018 has been used. The experiment was decided to be kept up to end of February 2020 in order not to have data influenced by the COVID-19 pandemic. The "raw" format of the data is represented in Figure 7. 


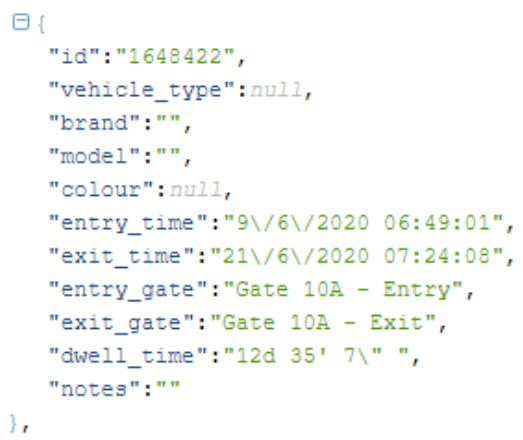

Figure 7. Data format of vehicles crossing the port gates.

Therefore, for using the data for the TCI, a pre-processing step was needed. Data from April 2018 was queried from the past entries/exits of vehicles and the same structure was established for real-time and future continuous usage of the composite index. The process consisted of retrieving all vehicles in the period, filtering by the "gate" field, analysing the timeframes they crossed through the gates (fields: "time"), establish hourly ranges and count afterwards the number of vehicles on that range. This exercise was materialised in Python scripts and the data digested was store in a proper database to later feed the model training according to the software design of the framework (see Section 3.1).

\subsubsection{Traffic at the City Provided as Open Data}

For including city traffic data from the surroundings of the port, the authors used an open data source consisting of digested information from car fleet equipped with Global Positioning System-GPS - providing location and speed information of the city of Thessaloniki. This data (with especial interest due to the historic offering) was served by courtesy of CERTH-HIT (member of PIXEL) via the TrafficThess website [105]. This website has varied information of the different roads of the city (referred as links) updated each $15 \mathrm{~min}$, which is perfectly aligned with the used baseline dataset for this task. The pre-processing followed over the raw data involved: (i) selecting five of the surrounding links to the gates of THPA, (ii) extracting the data for those five links from April 2018 till February 2020 (same reasoning than before), (iii) selecting the interesting fields of the information provided, (iv) building a Comma-Separated Value (CSV) table with the average of the average speeds of the 5 surrounding links. This is briefly illustrated through the images in Figure 8:

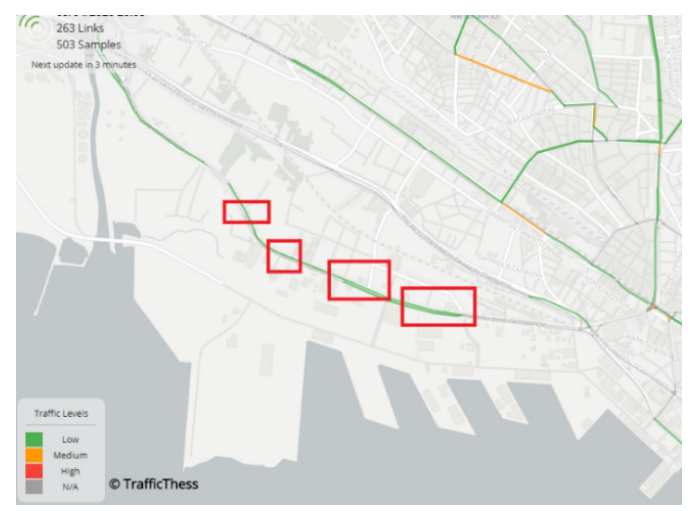

(a)

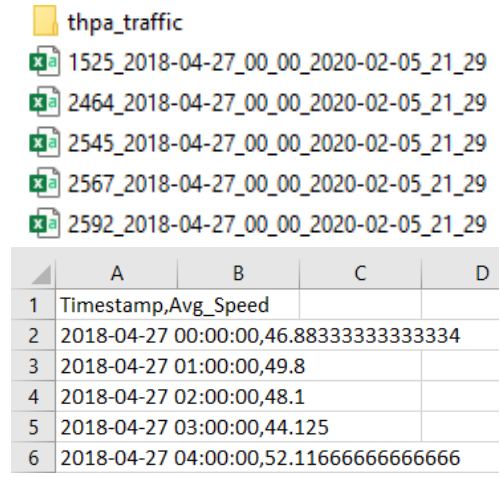

(b)

Figure 8. Traffic city data origin and procedure is shown as a figure, (a) Selected relevant surrounding links over the TrafficThess web interface; (b) Structure and management of historic data in CSV format. 
As explained, TrafficThess' historical is sampled every $15 \mathrm{~min}$. To make the calculations consistent, both historic and real-time data was averaged and condensed to have a 60-min granularity. Thereafter, the dataset was properly stored, ready to be used for TCI computation.

\subsubsection{Vessels Berthed in the Port}

Similar to the traffic at the gates of the port, the authors were provided with historic and real-time data of the vessels processed in the Port of Thessaloniki courtesy of the Port Authority. This data was served by the Information Technology department of the Port of Thessaloniki via a REST API web analogous to the previously mentioned. The query to that API returns all the vessels that were operated (one API per year) in a JavaScript Object Notation (JSON) format including rich information and details of every single vessel in a year. This information is only timestamp-referred by including fields of "start_work" and "end_work" of each ship, therefore certain data pre-processing after acquisition was needed. The procedure followed was: (i) downloading the data of all vessels processed in April 2018-February 2020, (ii) fine-tuning the timeframe, (iii) grouping, filtering and counting the vessels to prepare a CSV file the proper info: number of vessels at berth/manoeuvring in the port separated by periods of $60 \mathrm{~min}$ This is briefly illustrated through the images in Figure 9:

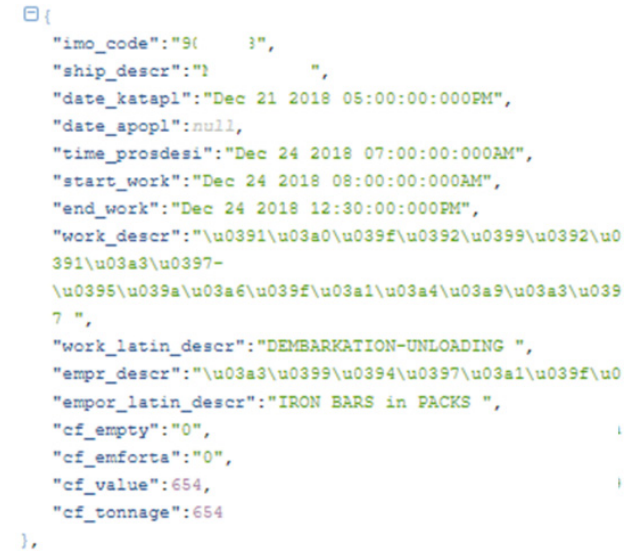

(a)

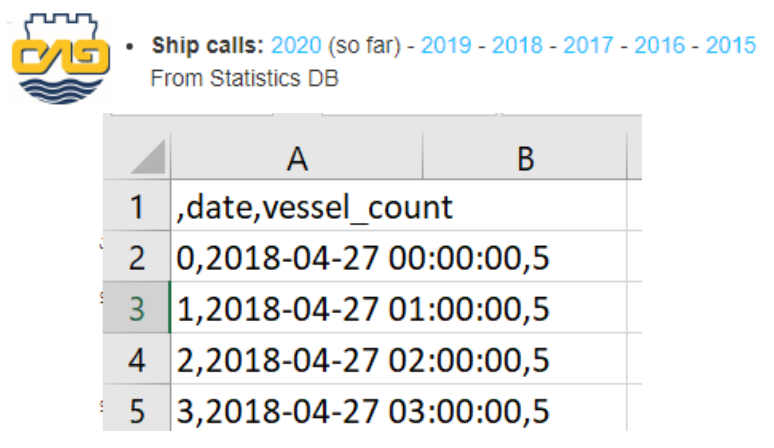

(b)

Figure 9. Vessel count per hour in the Port of Thessaloniki: (a) Raw data format; (b) Structure and management of historic CSV.

Regarding the pre-processing, most data from the raw retrieval was ignored except for counting the number of vessels in a timeframe. Filtering by the fields of "start" and "end" work, the dataset was built. The technology used for the pre-processing were Python scripts, taking advantage of the features of the library pandas.

\subsubsection{Weather}

The authors have used the free web service provided by Stratus Meteo of Greece [106]. Different sensors are installed throughout Greece and for this case we made use of the one closest to the Port of Thessaloniki (presented in Figure 10).

Historical and real-time measurements of temperature, wind speed, precipitation intensity, humidity and dew point (among others) were ready to use considering the following hindrances: the information retrieved from this external service was only served with a daily granularity. In that regard, a preliminary action needed was to re-shape the data to adjust the structure for the posterior modelling. Moreover, the dataset of weather was also available from September 2018, therefore diminishing the quantity of data for training and validating the model and the expected accuracy. 


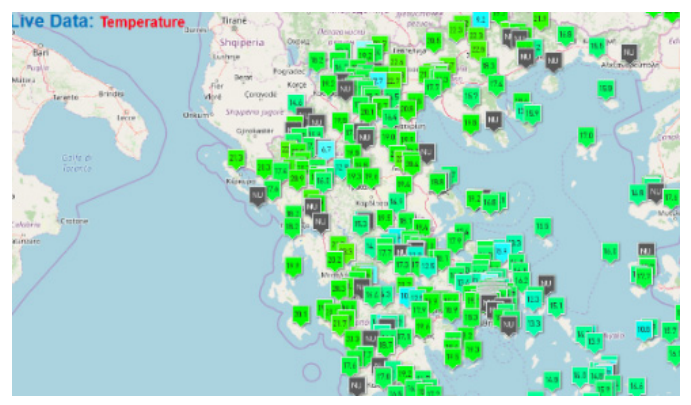

(a)

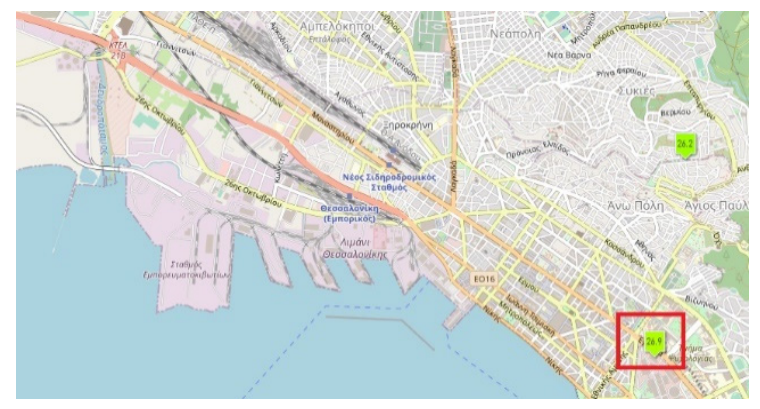

(b)

Figure 10. Selection of sensor data source for weather. (a) Global meteo sensor stations distributed throughout Greece; (b) Sensor selected close to the gates of the Port of Thessaloniki.

Table 3 shows a summary of the data that has been used for the experiment:

Table 3. Summary of data used in the experiment.

\begin{tabular}{cccccc}
\hline Data Source & $\begin{array}{c}\text { Technology } \\
\text { Used }\end{array}$ & $\begin{array}{c}\text { Relevant } \\
\text { Parameters }\end{array}$ & $\begin{array}{c}\text { Refresh Frequency of } \\
\text { Pre-Processed Data }\end{array}$ & Units & $\begin{array}{c}\text { History } \\
\text { Available }\end{array}$ \\
\hline Gates' traffic & RFID & Vehicles & Per hour & Vehicles/hour & April 2018 \\
\hline Weather & Meteo station & $\begin{array}{c}\text { Temp, wind speed, } \\
\text { precipitation } \\
\text { intensity }\end{array}$ & Per day & ${ }^{\circ} \mathrm{C}, \mathrm{kmh}, \mathrm{mm}$ & September 2018 \\
\hline City traffic & GPS & Average speed & Per hour & Kmh/vehicle & April 2018 \\
\hline Vessels in port & Vessel calls & Time ranges & Per hour & \# of vessels & April 2018 \\
\hline
\end{tabular}

\subsection{Methodology of the Experiment}

The experiment has consisted of deploying the framework of Section 3.1 for the use-case outlined in Section 3.2. To conduct the experiment, a methodology of various steps was envisaged and took place. The explanations below aim as well at being a guide-for-using for any person wishing to replicate a similar practical case using our framework.

On one hand, the "conceptual" methodology was comprised of the actions needed to be tackled by the involved people (port, city, citizens, societal agents). The idea is to have a useful CI that will lead relevant actors to set sustainable, smart policies upon it. Therefore, this activity is of paramount importance. For this experiment, the only actor that participated was the Port Authority of the Port of Thessaloniki, under the scope of the project PIXEL. The "conceptual methodology" has three steps, whose details are shown in Figure 11. The purple boxes represent the moments where the technical staff will need to intervene to guarantee effective deployment of the framework.

On the other hand, the framework had to be customized and instantiated for conducting the experiment. Apart from enough equipment material to run the modules integrated (see Section 3.4.4), the technical intervention went as follows:

1. Definition and development of the NGSI agents: developed by technical experts after gaining information of the data available (see Section 3.2).

2. Definition of the composite index (TCI) by stakeholders using the visual interfaces developed in the framework.

3. Setup and running of the predictive component, from user parameters to actual software running.

4. Configuration, implementation, and integration of all the pieces together to have a real-time composite index calculation.

In the next sub-sections, we are describing the materialization of the steps above for the experiment developed in this paper. 


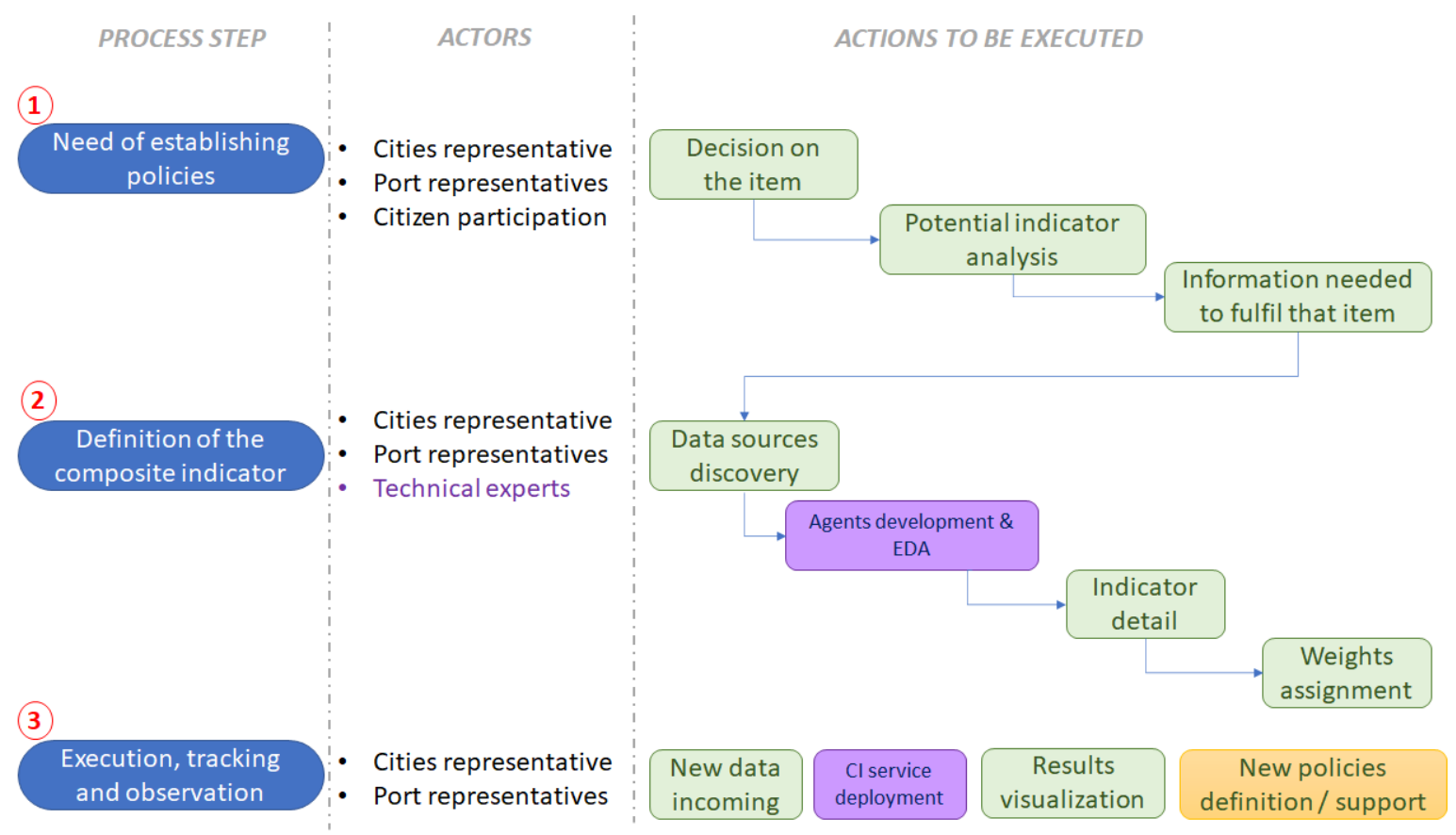

Figure 11. Conceptual methodology for deploying the framework on a practical experiment.

\subsubsection{Definition and Development of NGSI Agents for the TCI}

The technology selected to implement the NGSI agents was the Python pyngsi framework. It was developed as part of the H2020 PIXEL project. Writing a NGSI agent using this framework avoids developing them from scratch, because it offers a clean code structure and a documented tutorial. Therefore, the developer of an agent can focus on writing his own logic to build NGSI entities.

Figure 12 shows how the agents developed enable to process experiment data from heterogeneous data sources, content formats and protocols using a common interface, convert the data received in the NGSI entities based on FIWARE data models and send it to the Orion Context Broker. Specifically, for the use case, the data sources were two-fold: historic datasets consisted of structured CSV files while real-time data was to be retrieved by specific HTTP requests to REST APIs. This drove the authors to create two agents per data source: one for the historic and another for the real-time connection. In both, data was transformed in a JSON schema, covering the key-value representation of NGSI v2 context data. As designed in the framework (Section 3.1), the NGSI v2 data model defined is a custom extension of the KeyPerformanceIndicator FIWARE Data Model. It was extended following the design principles and guidelines offered by FIWARE official documentation [107].

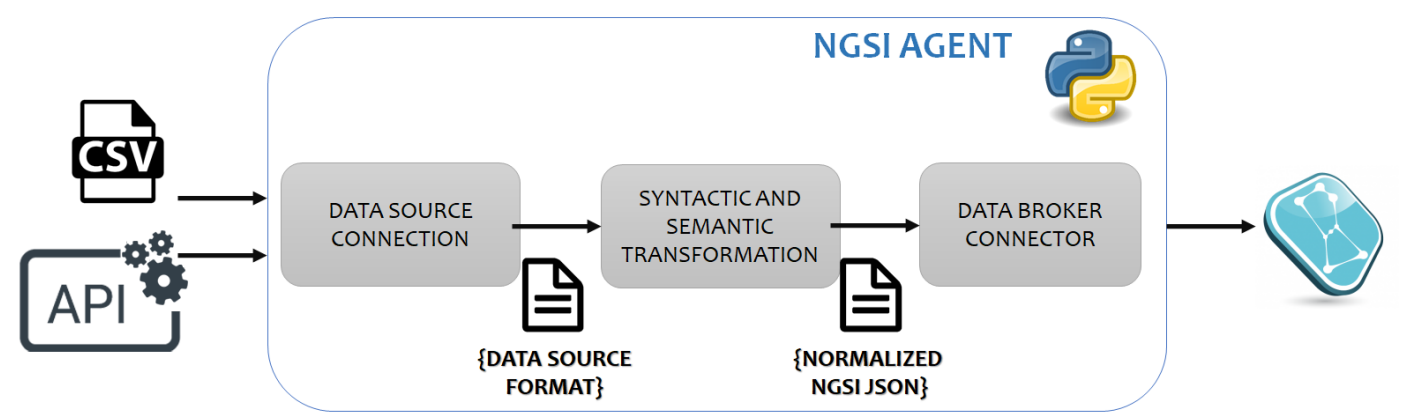

Figure 12. NGSI agent internal process for data conversion in the TCI experiment.

According to the previous, all NGSI agents needed to be developed in one experiment must follow the three-step processing. Within the syntactic and semantic transformation, several other 
computations such as filtering, grouping, cleaning, discarding may take place. Additionally, all interoperability agents have certain inseparable parameters, which are the refresh time (RT) and the "kpiName" field name. In the experiment of this paper, a total of seven agents were developed to ensure proper storage and usage of historic and real-time data. In Table 4 details are found of their development.

Table 4. Interoperability NGSI agents developed in the experiment.

\begin{tabular}{|c|c|c|c|c|c|}
\hline Data & Agent Type & Format & Transformation & RT & kpiName \\
\hline $\begin{array}{l}\text { Gates } \\
\text { traffic-Historic }\end{array}$ & $\begin{array}{l}\text { Active over } \\
\text { static file }\end{array}$ & CSV & $\begin{array}{l}\text { Pre-processing explained } \\
\text { in Section 3.3. }\end{array}$ & - & Kpi-traffic-gate-10A/16 \\
\hline $\begin{array}{l}\text { Gates } \\
\text { traffic-real-time }\end{array}$ & $\begin{array}{l}\text { Active over } \\
\text { dynamic source }\end{array}$ & REST API & $\begin{array}{l}\text { Filtering, grouping and } \\
\text { JSON conversion. }\end{array}$ & $60^{\prime}$ & Kpi-traffic-gate-10A/16 \\
\hline City traffic & $\begin{array}{l}\text { Active over } \\
\text { external } \\
\text { website }\end{array}$ & CSV & $\begin{array}{l}\text { Pre-processing explained } \\
\text { in Section } 3.3\end{array}$ & $60^{\prime}$ & Kpi-traffic-city \\
\hline Weather & $\begin{array}{l}\text { Active over } \\
\text { external } \\
\text { website }\end{array}$ & CSV & $\begin{array}{l}\text { Pre-processing explained } \\
\text { in Section } 3.3\end{array}$ & $24 \mathrm{~h}$ & $\begin{array}{l}\text { Kpi-weather-temperature } \\
\text {-windSpeed } \\
\text {-precipIntensity }\end{array}$ \\
\hline $\begin{array}{l}\text { Vessel } \\
\text { count-historic }\end{array}$ & $\begin{array}{l}\text { Active over } \\
\text { static file }\end{array}$ & CSV & $\begin{array}{l}\text { Pre-processing explained } \\
\text { in Section } 3.3\end{array}$ & - & Kpi-vessel-count \\
\hline $\begin{array}{l}\text { Vessel } \\
\text { count-real-time }\end{array}$ & $\begin{array}{l}\text { Active over } \\
\text { dynamic source }\end{array}$ & REST API & $\begin{array}{l}\text { Filtering, grouping and } \\
\text { JSON conversion. }\end{array}$ & $60^{\prime}$ & Kpi-vessel-count \\
\hline
\end{tabular}

\subsubsection{Definition of the Traffic Congestion Index}

According to the use-case definition, the TCI composite index represents the congestion status due to diverse factors. To build the CI structure, the authors proceeded to analyse the data, establish a levelled tree layout and weighted the nodes. This exercise must be tackled jointly by technical staff and stakeholders in a potential replication of the experiment.

- Grouping of data into KPIs: Following the state of the art analysed in the projects PIXEL and CITYkeys, the authors decided to group the data for feeding KPIs by common origin and meaning [99]. This drove the design to couple the traffic on one side (gates of the port and city), vessel information on other side and weather information on a third and final string. The leaf nodes (KPIs) were also individually separated by isolated pieces of information (Gate 16 of the port, Gate 10A of the port, vessel count, temperature, wind speed and precipitation intensity). This led to a three-levels composition, being the KPIs the leaf nodes, three subindices and the TCI as the root node, resulting in a 7:3:1 matrix.

- Exploratory Data Analysis (EDA) of available historical data: Authors carried out a thorough EDA of the historic of data (see Section 3.3). A summary of that EDA is attached in Appendix B. The main aim of this EDA was to discover how the data performs through time, noticing seasonality, and, mainly, to find the correlation between the different data with the main reference source: the traffic at the gates of the port. The results of this correlation were the following:

- Weighting: The last-but-one configuration for the CI was to select the weighting method and values to give to each node. This is a crucial action that has been widely studied in the composition of CIs [108]. There is not a universal weighting method and it must be analysed case by case, introducing a challenging choice [109]. The most used method is equal weighting, followed by analytical methods (regression analysis, benefit-of-doubt, principal component analysis), with opinion-based methods only used marginally. The choice depends on the nature of data and indicator items: (i) equal weighting tends to be used when no historical data is known, (ii) analytical methods are case-to-case analysed depending on the items and (iii) opinion-based methods are mostly used in social sciences (cases where the target indicator is highly subjective). In this experiment, the authors opted for an analytical method driven by the analysis of historic 
data available. The specific scheme selected was to base the weighting values on the correlation of all items with the main reference item. For establishing those values, $g$ the authors came to map KPI-weight, sub-index-weight, which brought to solve three equations systems (see numbers and structure of the points above).

$$
\sum W i \times C o r r i-o t h e r \_s o u r c e s \_i n \_s t r i n g=1
$$

The relation among KPIs is known by Table 5, therefore the Gauss method was used to solve them and come up with the weights, which are displayed in Figure 13.

- Aggregation method: According to the literature, there are three widely used aggregation methods [108]: additive aggregation, geometric aggregation and non-compensatory aggregation, being the first one the most popular by far. Additive aggregation provides transparency and allows a simple understanding of the results, being much dependent on the synergies between items. Geometric aggregation also provides a good understanding of results but requires uniformity in measurement units and scales, being very dependent of synergies as well. Non-compensatory methods are fit for cases where the indicator is going to be deployed in several instances (e.g., ports, countries) and those aim to be compared and ranked. Non-compensatory methods are the most computationally expensive of the three. For this experiment, the authors considered that the relevance of all indicators was not equal, being the traffic at the gates the reference item. Noticing the previous, the choice was to select additive aggregation. However, the framework developed in this paper has been designed to allow the selection of any of them for future uses.

- Normalization method: The items to build the indicator must be comprehended in the same scale in order to be aggregated. Thus, a normalization step was included in this computation. A lot of methods for normalization are available, and to be able to finally select one as definitive several robustness test must be done. The objective of the work in this paper was to demonstrate the use of these calculations using a specific IoT architecture rather than going deep into normalisation arguments. Scale method was discarded due to magnitude variation, as well as the ranking due to its only execution in Thessaloniki. Z-score method and Min-Max were the main candidates and, considering that in this experiment the authors had valuable historic data for more than 18 months, the Min-Max option was selected.

Table 5. Correlation between all data sources with the traffic at the gates of the port.

\begin{tabular}{cll}
\hline Source & Correlation & \multicolumn{1}{c}{ Explanation } \\
\hline Average speed in nearby streets & $-19.2 \%$ & $\begin{array}{l}\text { As the cars move slower (less speed), the } \\
\text { more traffic at the gates is experienced, } \\
\text { being the most statistically relevant factor } \\
\text { influencing the congestion }\end{array}$ \\
\hline Number of vessels berthed & $+11.7 \%$ & $\begin{array}{l}\text { More vessels at the berth, more traffic at the } \\
\text { gates. Although the correlation is not high, } \\
\text { this \% is significant. }\end{array}$ \\
\hline Temperature & $\begin{array}{l}\text { The colder, the more traffic, which under a } \\
\text { logical point of view: summer-less traffic. } \\
\text { Not much statistical impact. }\end{array}$ \\
\hline Wind speed & $-7.7 \%$ & $\begin{array}{l}\text { The winder, the less traffic, but with no } \\
\text { relevant relation to be conclusive. }\end{array}$ \\
\hline Precipitation intensity & $\begin{array}{l}\text { Very loosely coupled, almost no statistical } \\
\text { correlation. }\end{array}$ \\
\hline
\end{tabular}




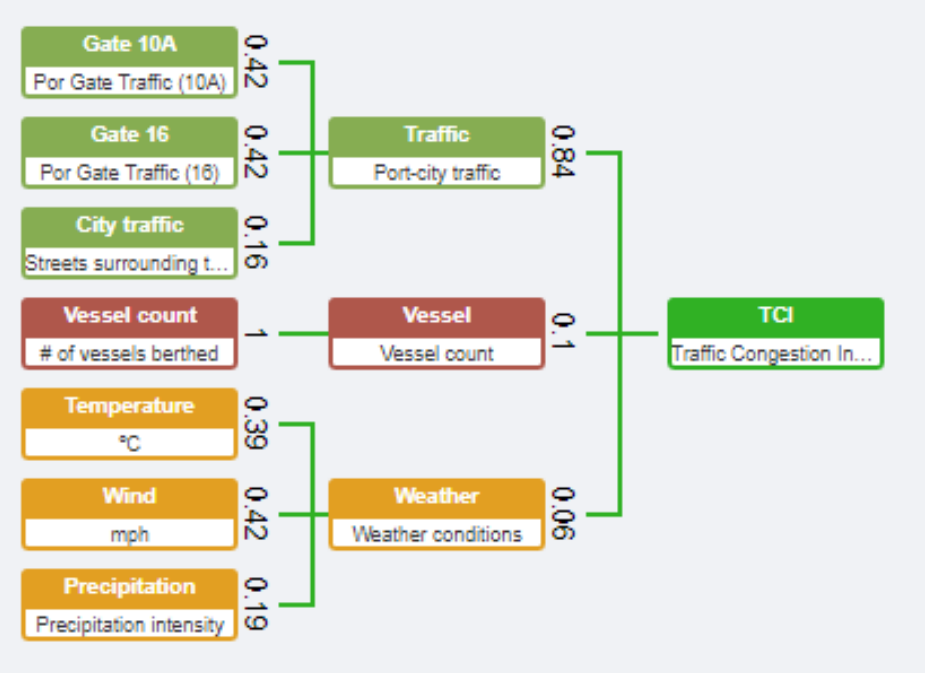

Figure 13. Tree definition and weighting for calculating the Traffic Congestion Index.

\subsubsection{Predictive Component: Training and Validation}

In the scope of the composite indicators using the proposed framework, the prediction will always drill down as a timeseries forecasting problem. According to the revision outlined in Section 2.4, in this case, a model must be trained with past data and requested to infer new values for a certain horizon using the same period than the available dataset, so a custom predictive model had to be used by transforming timeseries problem into a classical structured supervised ML problem. In those, no fresh data is required as input to a "prediction black box" to influence the prediction. Therefore, what must be done is re-train the model periodically to be sure to be exploiting the new data as much as possible.

For this experiment (see Section 3.3), the periodicity of data is $60 \mathrm{~min}$ (except for weather, that is daily). Thus, it was decided by the authors to establish $60 \mathrm{~min}$ as the periodicity and one day as the horizon.

Regarding the selection of the model, several options were available (see Section 2.4). Especially interesting were Autoregressive Integrated Moving Average-ARIMA—-models or time series regression models such us Seasonal ARIMA (SARIMA) or Autoregression Vector [110], among others, widely available in Python libraries in the open-source community. Authors realized, thanks to the EDA, that some data registers presented missing values. Besides, both traffic in the city and weather data presented strong daily and monthly seasonality. Henceforth, a model engine needed to be selected that properly handled those criteria. According to the authors, the most appropriate selection was to use Prophet [111], a general purpose timeseries forecasting tool developed by Facebook. This election was strengthened while observing some of its traits: easily integrable in agile deployments with heterogeneous data. Detailed analysis of the use of other state-of-the-art models such as gradient methods were applied in one activity of PIXEL project [112], which outperformed Facebook Prophet by significant margins, but required more effort and data to be integrated, hindering the automation capacity and seeming overkill targets for what is needed in a Smart Port-City CI application.

Regarding re-training and evaluation, the framework has been designed to be re-trained under request. At each re-training iteration, the model will be evaluated on left-out datasets following a 70/30 dataset split, using different error metrics. For this experiment, the model was re-trained three times, resulting in a validation that can be consulted in the repository of the materials of the paper:

(1) To convert and clean the historic CSVs into the accepted data format for training the Prophet model. Here, the attributes had to be adapted and seven different models were created. The framework and methodology designed (see Section 3.1) established that all KPIs must be predicted, and then the $\mathrm{CI}$ is calculated after those values. For that reason, one model per each KPI was trained and 
used. This was developed by the authors using Jupyter Notebooks [113]. The procedure was studied to be replicated in an automated way for (2).

(2) To create Python scripts that gather and group the KPIs data from the data storage and convert, clean, and adapt the information for re-training the seven models. In this experiment, three re-trainings took place, according to the framework usability evaluation depicted at the beginning of Section 4. The outcomes were new models that have used more historic data to be trained, therefore more accurate and usable. For storing and retrieving those models (binary files), the Python built-in library pickle has been used.

(3) To apply the models. As commented, the forecasting horizon was set to 1 day with a $60 \mathrm{~min}$ periodicity. This way, each morning, the framework runs the inference over the trained models. Prophet models do not need input data; therefore, a prediction is requested (automated through a Python script) with that periodicity and horizon. The outcome (future timestamps with predicted TCI values) are used to be represented for the user via the UI component.

\subsubsection{Component Integration and Deployment}

When all modules were developed and ready to be used from an isolated perspective, then the authors proceeded to the integration and deployment. Using the authors' university department own premises, a prototype of the framework was deployed to run the use-case of the experiment. The different modules (as designed in Section 3.1) were integrated, connected using the proper ports and following the containerization (Docker) approach, resulting on a continuous working system. The schema of Figure 14 aims at representing the module interactions, data flow and "network configuration" of the deployment of the framework for this case.

As it can be seen, the deployment follows the design of Figure 2 (Section 3.1), keeping consistency with horizontal and vertical competences of every module. However, it is worth to mention that some additional elements - not explicitly stated in the framework design — were needed to achieve effective integration. These additional elements, and a summary of the integration flow, are narrated below.

The NGSI Agents retrieved the raw data from the different origins, converted them into the proper format based in the FIWARE KPI datamodel, and then updated the attributes of the related FIWARE ORION entity. As one mandatory addition, the Data Broker modules had an associated MongoDB database. This database is embedded natively with ORION in order to persist the last value of the entities' attributes, which is named context data. Afterwards, to be able to connect the Data Broker with the long-term storage database of the framework (Elasticsearch), another auxiliary element was required: FIWARE Cygnus [114]. This component subscribed to the ORION entities and created a sink to connect with the upper-layer database. With that purpose, the NGSIElasticsearchSink [115] was used.

The orchestrator module was deployed as a crucial piece of the framework. The integration consisted of properly using Linux cron job to schedule the prediction scripts and TCI calculation.

Atop those, the Elasticsearch REST API module—another additional element—was needed to act as a bridge between the data storage module and the visualization UI. It was built using NodeJS [116] and the Elasticsearch Node.js client [117], with the purpose of avoiding queries to Elasticsearch directly from the UI. This module prepares the data with the specific format used by the map and the different charts that are displayed in the dashboard section of the UI and stores the tree specification in the database. Finally, the UI was served like a static web page by an Apache Server [118], so it was able to be accessed by the users via a common web browser. This web browser makes the necessary requests to the Elasticsearch API module.

Regarding technical details of the deployment, all the modules were deployed in the same machine, except the data source REST APIs (city traffic, weather and THPA). This machine belongs to the authors' investigation group private cloud and its hardware specifications are detailed in the Table 6. In addition, both the software specifications of the pre-built modules (FIWARE components and Apache Server) and of the technologies used to develop and run the other modules are detailed in the Table 7. 


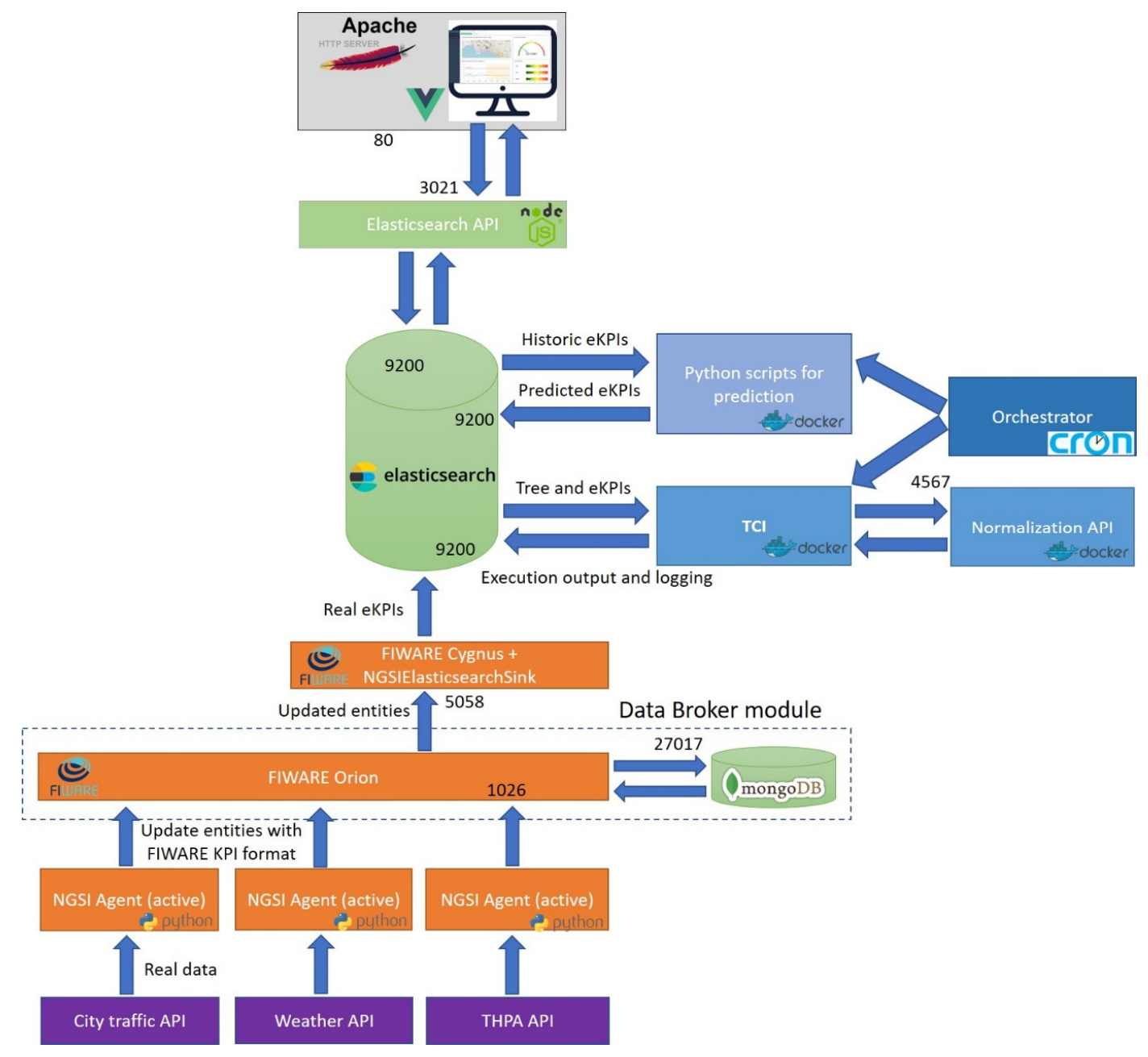

Figure 14. Integration and deployment of the framework for running the experiment.

Table 6. Hardware specifications of the server.

\begin{tabular}{cc}
\hline Item & Specifications \\
\hline CPU & 4 CPUs $x$ Intel ${ }^{\circledR}$ Xeon ${ }^{\circledR}$ CPU E3-1220 v5 @ 3.00 GHz \\
Storage Memory & HDD 100 GB \\
RAM Memory & 16.05 GB \\
Cluster & FUJITSU PRIMERGY TX1330 M2 \\
\hline
\end{tabular}

Table 7. Software specifications of the framework.

\begin{tabular}{cc}
\hline Item & Specifications/Version \\
\hline Server OS & Ubuntu Server 18.04.4 LTS \\
Java & OpenJDK 1.8.0_252 \\
Apache Maven & 3.5 .4 \\
Node.js + npm & 12.18 .1 LTS +6.14 .5 \\
Python + pip & $3.8 .3+20.1 .1$ \\
Docker + Compose & $18.09 .7+1.17 .1$ \\
Apache Server & 2.4 .43 \\
Elasticsearch & 7.8 .0 \\
MongoDB & 3.6 .3 \\
FIWARE Orion & 3.4 .0 \\
FIWARE Cygnus & 2.2 .0 \\
Development IDEs & Eclipse IDE for Enterprise Java Developers (v. 2020-06) \\
\hline
\end{tabular}




\subsubsection{User Configuration}

Once the modules are integrated and the deployment is set, the last step of the methodology was to adjust the visualization and other configurations to interpret the CI. These configurations-in a supposed replication of the experiment - must be done by the actors interested in the composite index. In this experiment, the authors took the liberty to configure the solution assuming how it might be used by such actors. There were two configurations, and all was enabled to be set via user interface:

(1). To translate the CI calculation configurations for actionable instructions

The TCI definition is explained in Section 3.4.2. The CI structure and weights were there defined from an operational point of view. The configuration at this step meant to translate that definition into software instructions. There, the authors created the number of levels of the tree and then, create all the tree nodes, beginning from the root node and finalizing in the leaf nodes. For each node, it was introduced the name (in leaf nodes, it must coincide with the name of a valid KPI stored previously in the Elasticsearch database), description and, depending of the node level, the weight, weighting method, aggregation method and NGSI Agent. Furthermore, it was necessary to select a common normalization method and to introduce the URL of the normalization API, needed to run the TCI (Figure 15). The selected normalization method for the experiment was Min-Max [119] per KPI.

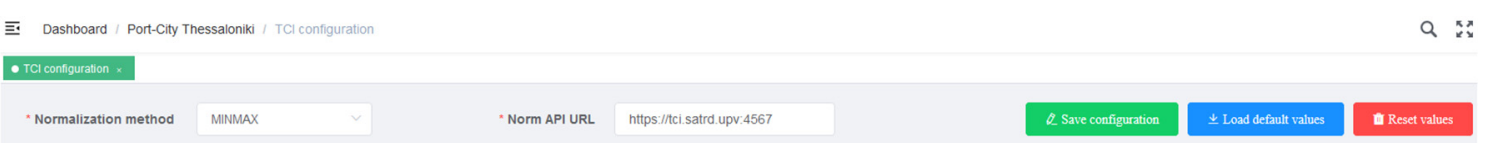

(a)

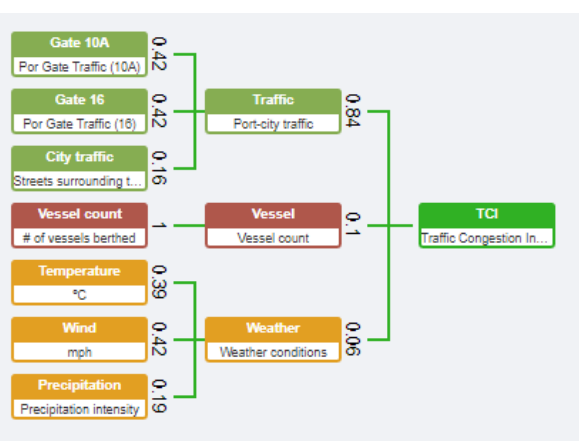

(b)

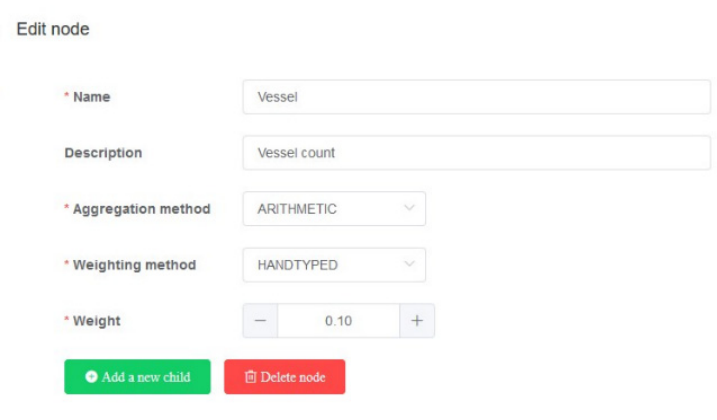

(c)

Figure 15. Composite indicator configurations: (a) normalization method and API; (b) tree structure creation, from results of Section 3.4.2; (c) configuration for each node of the TCI tree.

(2). To establish thresholds, reference numbers in the visualization of results

Another section of the UI where the authors stated configuration parameters was the dashboard, that will be explained in detail in the Section 4. The authors inserted the threshold values for low and high traffic in the line graph and the threshold values of traffic at the gates that will be translated to the gates' color in the map (Figure 16). For the experiment, the configuration values selected were:

$$
\begin{gathered}
0 \leq \mathrm{TCI}<0.2, \text { Low congestion } \\
0.2 \leq \mathrm{TCI}<0.46, \text { Medium congestion } \\
0.46 \leq \mathrm{TCI}<1 \text {, High congestion }
\end{gathered}
$$




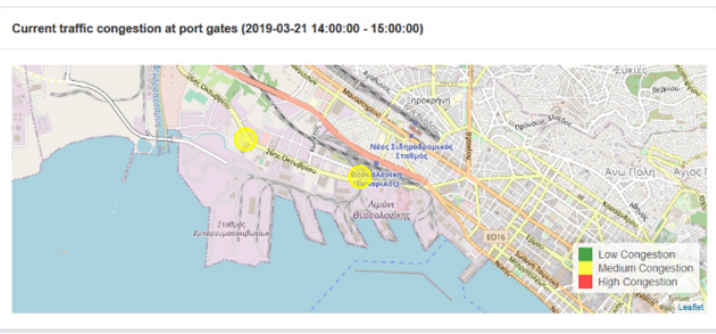

(a)

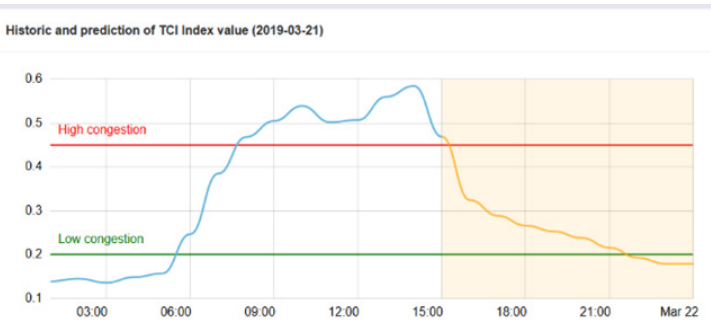

(b)

Figure 16. Configuration of thresholds: (a) for the representation of current status in a map; (b) for visualizing margins of TCI evolution and prediction.

\section{Results}

The objective of the proposed framework was to provide usable, reliable, actionable knowledge via a composite indicator. The experiment deployment presented above was aimed at demonstrating the usefulness of the framework. Therefore, results were needed to validate that objective.

In the context of the TCI, the traits that had to be analysed were:

(i) composite indicator makes global sense and represents the reality,

(ii) predictions are valid and realistic, so that the model can be trusted, and

(iii) the interface usability makes it easy to interpret the information to build Smart Port-City policies upon.

As explained in Section 3.3, the historical data in the experiment covers from April 2018 to February 2020 (except for the weather, which is available from September 2018). From that point on (February 2020), this framework was designed, and the data from that moment was gathered in real-time. The Port and the City of Thessaloniki have certain seasonality patterns on the traffic and weather, therefore, in order to validate the framework, the strategic choice was made to select certain dates to obtain results to analyse. Drawing from the EDA carried out, it was noticed that summer months' performance varied in comparison to winter months; diverse variation within the week and the hour of the day were also observed. Henceforth, it was decided to define 9 scenarios to cover most of the situations that the port-city traffic might experience. Specifically, three timeframes were selected (one week in March, another in August and another in January), selecting three different days at three different hours. The dates selected were Tuesday at 9 a.m., to represent a busy period with regards to vessel operations and traffic at the gates, Thursday at 3 p.m. to reflect moderate traffic period (at average) and Saturday to reflect low port activity and high city life. This way, authors aimed at having enough base to reassure whether the framework will be valid.

For visualising the results, the authors created a UI dashboard, as contemplated in the top-layer component of the framework. It is shown in Figure 17, representing the results of scenario 1.1.

The first quadrant is titled "Current traffic congestion at port gates" and it is formed of an OpenstreetMap [120], which has been created using the library Leaflet [121], including two markers that correspond with the location of the two gates (10A and 16, from left to right) that are analysed. The markers' color indicates the congestion level in its corresponding gate. At its right, the gauge chart shows the current value of the TCI index. The third quadrant is titled "Historic and prediction of TCI index value". This line graph shows the evolution of the TCI in the whole day and it is split into two parts: the first one represents real values until the current time while the second one represents predicted values. Furthermore, the graph includes two lines that indicate the upper (red color and TCI value of 0.45 ) and lower (green color and TCI value of 0.2 ) thresholds. Finally, the bullet chart represents the current value of the three indices (traffic, vessels, and weather) obtained during the TCI calculation process. Most quadrants' interfaces of this visualization UI have been created using the library amCharts [122]. 

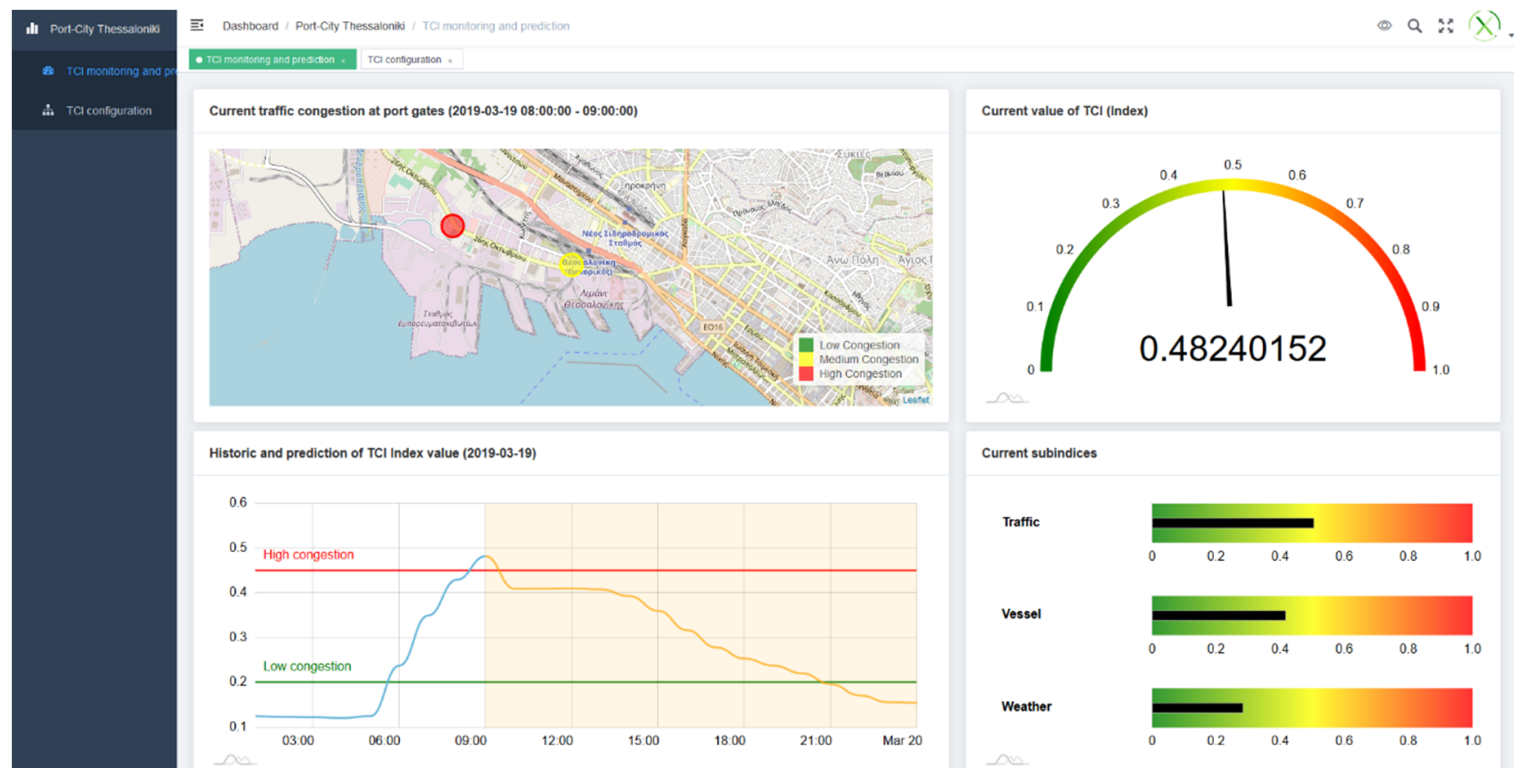

Figure 17. UI dashboard to visualise and interpret the calculation and prediction of the TCI.

According to the authors, the previous screen enables the port and city stakeholders to interpret the current and the short-term predicted evolution of the traffic congestion. Stakeholders will be able, then, with this framework, to realise the real-timeness of the indicator, being able to make timely comparisons and knowing, with a quick glance, the status of the congestion in the port-city interface. The objective (iii) was met.

The same exercise was repeated for the nine mentioned scenarios, obtaining, for each, the value of the TCI on that moment and the predicted TCI values (thus its expected evolution) for the rest of that day (find all the screenshots in Appendix C). In the table below, there is a summary of the results and main conclusions extracted upon them. The rationale behind the column "Explanation and evolution" comes from the EDA. In general, the TIC values (and short-term prediction) are considered valid if it can be established a direct reasoning from the conclusions extracted during the EDA.

Observing the results in Table 8 and Figure 18, the objective (i) can be considered achieved. The value of the index is always comprehended in the $0-1$ range, indicating 1 as maximum traffic congestion and 0 minimum traffic congestion. In general, values are higher on labor days and lower on weekends, experiencing more traffic congestion in the mornings. The graph below aims at representing those values.

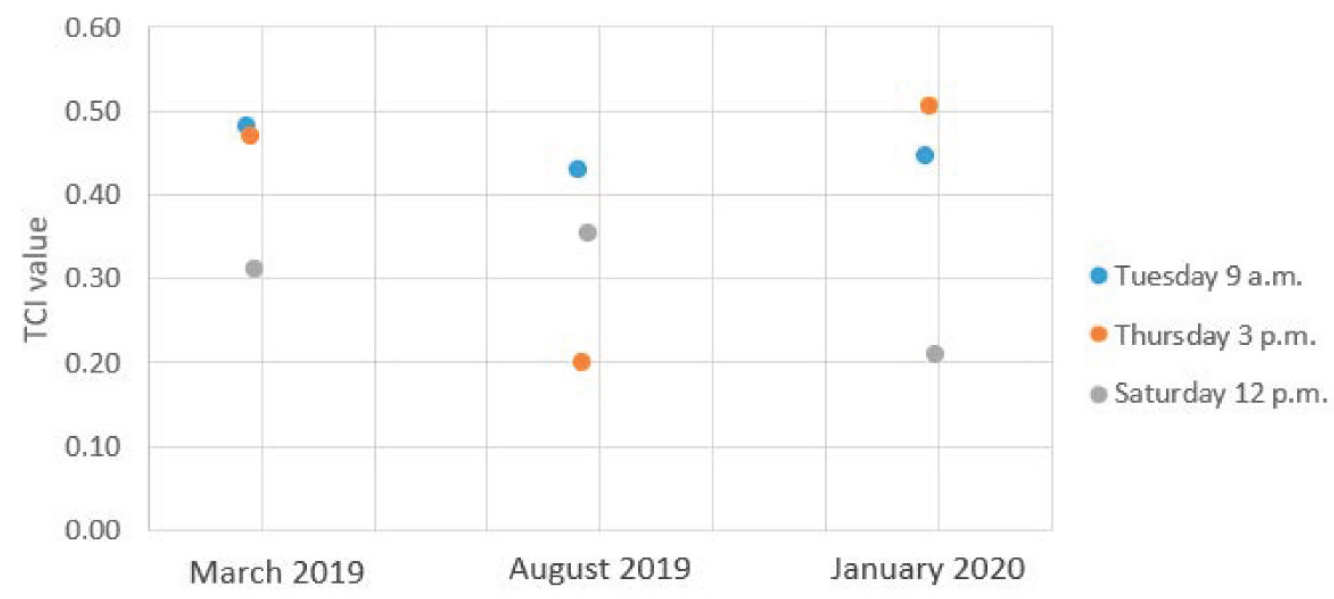

Figure 18. Results of the experiment-graph of TCI values per scenario. 
Table 8. Experiment results, reasoned per scenario.

\begin{tabular}{|c|c|c|c|}
\hline Sc.\# & Date & TCI Value & Explanation and Evolution \\
\hline 1.1 & $\begin{array}{l}19 \text { March } 2019 \\
9 \text { a.m. }\end{array}$ & 0.48240252 & $\begin{array}{l}\text { Peak is observed at the hour of the scenario execution, } \\
\text { which is aligned with the EDA and the expected } \\
\text { situation. The curve is a bit more flattened than logically } \\
\text { expected, but downwards timing seems proper. }\end{array}$ \\
\hline 1.2 & $\begin{array}{l}21 \text { March } 2019 \\
\text { 3 p.m. }\end{array}$ & 0.46978970 & $\begin{array}{l}\text { The hour of the scenario is exactly experiencing the start } \\
\text { of congestion dawn, where the peak was reach just } \\
\text { before } 3 \text { p.m. The prediction curve looks proper. }\end{array}$ \\
\hline 1.3 & $\begin{array}{l}23 \text { March } 2019 \\
12 \text { p.m. }\end{array}$ & 0.31322503 & $\begin{array}{l}\text { Scenario } 1.3 \text { can be trusted as well as the prediction for } \\
\text { the central hours ( } 9 \text { to } 15) \text { experiences usual up and } \\
\text { downs and it is kept between mid-congestion margins. }\end{array}$ \\
\hline 2.1 & $\begin{array}{l}13 \text { August } 2019 \\
9 \text { a.m. }\end{array}$ & 0.43149143 & $\begin{array}{l}\text { As a usual Tuesday, levels of congestion remain constant } \\
\text { high levels during the labor days. Curve reflects with } \\
\text { high accuracy the usual picture in vessel-operations busy } \\
\text { months. }\end{array}$ \\
\hline 2.2 & $\begin{array}{l}15 \text { August } 2019 \\
\text { 3 p.m. }\end{array}$ & 0.20111357 & $\begin{array}{l}\text { Scenario } 2.2 \text { shows unusual representation: despite } \\
\text { being a Thursday, the traffic congestion is experienced } \\
\text { and predicted between } 0.2 \text { and } 0.3 \text {. However, this must } \\
\text { be considered nothing but a good functioning of the } \\
\text { framework and the prediction, as the } 15 \text { th August is } \\
\text { national holy day in Greece. }\end{array}$ \\
\hline 2.3 & $\begin{array}{l}17 \text { August } 2019 \\
12 \text { p.m. }\end{array}$ & 0.35446125 & $\begin{array}{l}\text { Scenario } 2.3 \text { follows the same rationale than } 1.3 \text {, } \\
\text { therefore it is valid. The only addition is that more traffic } \\
\text { congestion (in general), is perceived and forecasted. This } \\
\text { makes sense as } 17 \text { th August is summer period and, } \\
\text { normally, more traffic is experienced in the city on } \\
\text { Saturdays at central hours. }\end{array}$ \\
\hline 3.1 & $\begin{array}{l}\text { 14 January } 2020 \\
9 \text { a.m. }\end{array}$ & 0.44768116 & Same exact observation, thus rationale than 2.1. \\
\hline 3.2 & $\begin{array}{l}16 \text { January } 2020 \\
\text { 3 p.m. }\end{array}$ & 0.50527066 & $\begin{array}{l}\text { As in } 1.2, \text { hour of experiment coincides with congestion } \\
\text { dawn. Curve looks legit. }\end{array}$ \\
\hline 3.3 & $\begin{array}{l}18 \text { January } 2020 \\
12 \text { p.m. }\end{array}$ & 0.21129410 & $\begin{array}{l}\text { Scenario } 3.3 \text { registered one of the lowest TCIs, both at the } \\
\text { measurement hour and in the real-time previous values } \\
\text { and the forecasted (max. } 0.3 \text { ). This makes sense as } \\
\text { winter's Saturdays are less congested (in general) than } \\
\text { the rest of the days. City's weekend tourist life is not as } \\
\text { vibrant as at summer. }\end{array}$ \\
\hline
\end{tabular}

With regards to the last objective, (ii), the "explanation and evolution" column in Table 8 details how the prediction of the TCI meets the logical expected curve. Besides, the performance metrics obtained of the model utilised show little error (Mean Absolute Error-MAE), especially in the most significant data references: traffic at port gates and traffic at port city.

As a point of discussion and utility of the framework, the technical solution developed provides an extension component for PIXEL platform, a potential enabler of FIWARE stack [123] and could be offered as an independent software tool atop those platforms.

Those facts together make the authors conclude, that, on the light of the results, the TCI experiment demonstrates that the proposed framework and methodology might help tackling current and future Smart Port-City challenges.

\section{Discussion}

The authors believe that the outcomes of this work might hugely contribute to cities and ports by implementing an IoT-based solution, which is the main focus of this special issue. Specifically, the TCI experiment carried out may support the effective implementation of policies in the city of Thessaloniki. To mention one, the TCI can be used in the reports of the port and the city to evaluate how the different urban planning initiatives or port land construction works are affecting the traffic in the surroundings. Another port-city policy that could be fed with the TCI are the citizens' safety associated to noise and pollution levels attributable to that port-city interface. From another perspective, the TCI value could 
be incorporated to the traffic lights cycle, allowing thus to reduce the congestion which might be a policy objective.

For a port authority, a deployment following the line of this TCI experiment can bring several benefits: first, having a unique point combining a series of relevant available resources, after its collection, having it monitored and published; second, being able (through data analysis) to identify periods of time in which the traffic is above accepted levels, focusing on the areas or procedures that can be optimized, correlating between processes and corresponding equipment, giving priority to areas (or procedures) with realistic reduction potential and thus optimising inbound and outbound truck flows and equipment movements; third, to establish internal process-centric practices, such as gate policies to specify a time slot during which trucks are allowed to enter the port area or relationship-centric practices, such as training operators (of machinery, vehicles, etc.) with the goal of minimising bad practices leading to higher traffic congestion that can have a negative environmental impact. Last but not least, visibility and acceptance from the community. From the municipality perspective, the TCI can be useful for another set of targets. Understanding the main contributor to the traffic congestion may help the administration to apply tailored control, influencing demographics, urban development, taxes or fines. Public bodies may also benefit from experiments like the TCI as a tool for auditing performance and ensuring to keep traffic levels among reasonable thresholds. Additionally, the semaphores and other signaling rhythms adjusting systems would have another input to be fed from. Finally, as a joint benefit, linking with the hypothesis proposed in this paper, the TCI may serve as a meeting point for all the actors above to know the current status of traffic congestion and to agree upon policies.

\section{Conclusions and Future Research Lines}

In this research, the authors have analysed the related work on the fields of smart port and smart city services, looking for finding a software-based solution to address relevant challenges of the smart port-cities of the future. The work was devoted to developing a framework to leverage IoT techniques focusing on the calculation and prediction of indicators representing real-world phenomena. In particular, as an outcome of this paper, the solution has been applied to real data on the port-city interface of Thessaloniki in Greece.

IoT open-source components have been used in the design and deployment of the framework, introducing elements for enabling short-term prediction, high usability and configuration capabilities for the user and an interpretation interface. Heterogeneous data sources have been handled using specific defined data formats, achieving syntactic and semantic interoperability. The software has been successfully integrated in virtualised servers hosted in one machine by the authors. Results were satisfactory in all the scenarios defined for the framework validation.

According to the authors, this field of work will open a wide variety of options to be explored, both from the application point of view (different actors, usability, standardization, methodology) and from the technical perspective.

On the one hand, the co-design and flexibility of the system will allow incorporating data and wills from different actors. For the citizens, having access to such an indicator would mean a step forward in the democratisation of the information and procedures, which can increase the acceptance of the government and of the port activities. This concept aims at boosting the so-called "enlightened political participation" [124] of the citizens to affect the decisions on their environment beyond the periodic voting. This is clearly a field to explore further as the outcome of this paper will offer the citizens and other entities the possibility to access and actively participate in such actions.

On the other hand, additional options for technology research are motley. Specifically, authors would be interested on see this framework as a basis for including more complex prediction models, a higher number of data sources and with more refined orchestration approaches. Regarding the framework composition, the authors believe that the dual approach designed will open interesting research lines; there is a trend in the distributed systems to move computation to the "edge" of the 
network to bring benefits such as reducing latency, optimizing bandwidth use, improving privacy and security, and alleviating network congestion and traffic in general [125]. In future applications, heavier training and predictions will be moved to the "NGSI agent side" of the system, allowing the central server to process, offer and show more data sources with more accuracy degree closer to real real-time. The fact of being built upon open source consolidated technologies makes the proposed tool a perfect testbed to be leveraged by the community, going beyond classical private customized approaches.

Author Contributions: Conceptualization, I.L. and A.B.; methodology, I.L..; software, I.L. and R.V.; validation, A.B.; formal analysis, I.L. and C.E.P.; investigation, A.B.; data curation, I.L.; writing-original draft preparation, I.L. and A.B.; writing-review and editing, C.E.P. and R.V.; visualization, R.V.; supervision, C.E.P.; project administration, C.E.P. All authors have read and agreed to the published version of the manuscript.

Funding: This research was funded, by the European Commission, via the agency INEA, under the H2020-project PIXEL, grant number 769355, and, when applicable, by the H2020-project DataPorts, grant number 871493, via the DG-CONNECT agency.

Acknowledgments: The authors extend their appreciation to the Port Authority of the port of Thessaloniki, to the National Observatory of Athens and to the HIT department of the Greek institute CERTH, for providing data to conduct the experiment under a collaborative spirit drawing from the scope of the project PIXEL (copyright compliance was obtained through publication of deliverable D4.4 of the project).

Conflicts of Interest: The authors declare no conflict of interest. The funders had no role in the design of the study; in the collection, analyses, or interpretation of data; in the writing of the manuscript, or in the decision to publish the results.

\section{Appendix A}

This appendix refers to the data models defined and used in this paper in the framework design and in the use-cases experimentation.

(i) Example of KPI used in the experiment (Traffic at Gate10A of the Port)—extension of KeyPerformanceIndicator JSON by FIWARE.

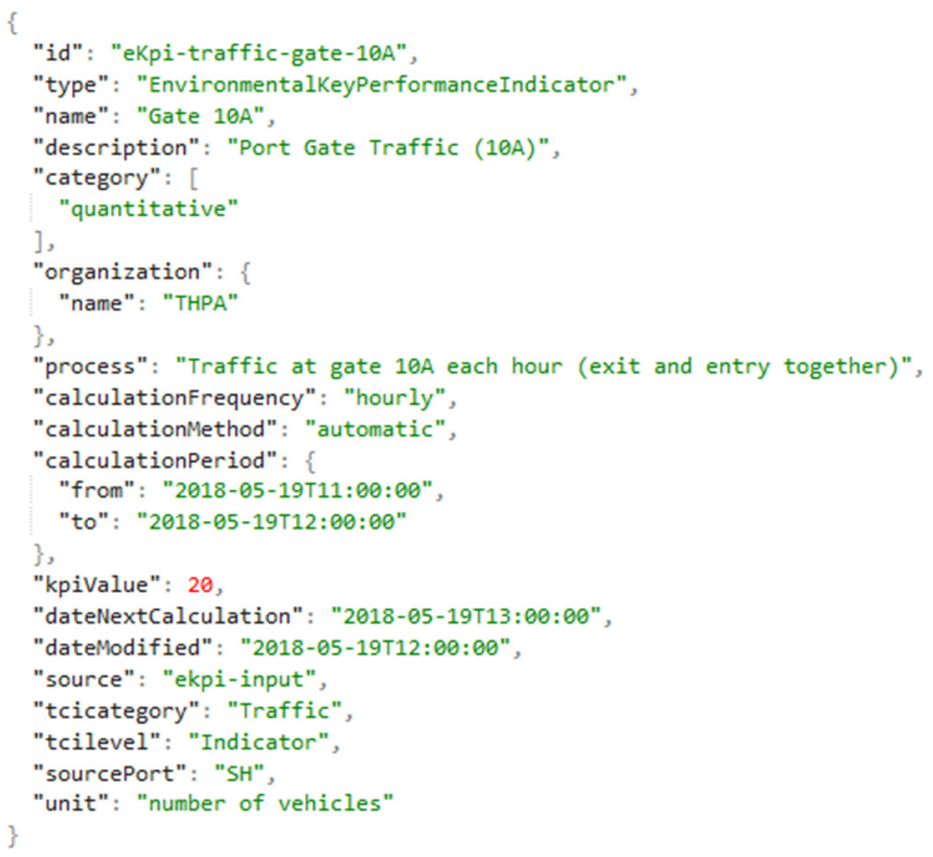

Figure A1. Example of an KPI datamodel.

(ii) Example of result after TCI calculation in the experiment. As in the previous, the FIWARE data model is also used as a basis, as we consider the TCI as another indicator (just the final single one): 


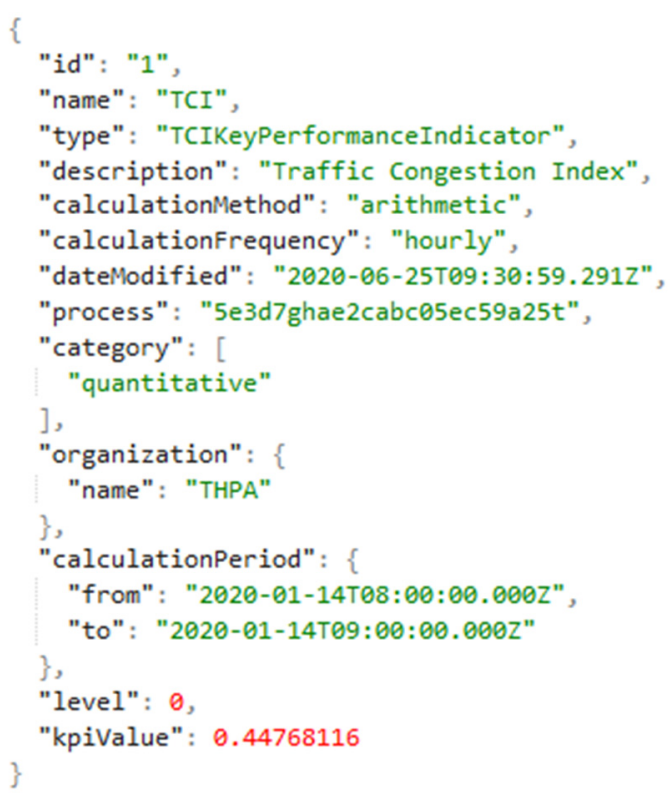

Figure A2. Example of an output KPI generated by the TCI.

\section{Appendix B}

This appendix aims at summarising the Exploratory Data Analysis of the baseline information (the most relevant: the traffic of the gates of the port) that was carried out by the authors to realise about data nature (performance in time, seasonality, patterns, etc.). This was conducted via the application of usual data science techniques, using Jupyter Notebooks and the library pandas.

For this analysis, the technical team assumed that there was no major differences (per average) on the gates behaviour within a certain month. Therefore, only Gate10A's results are shown.

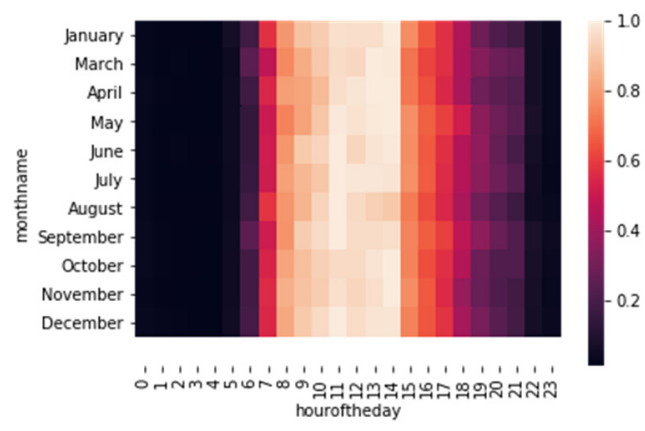

(a)

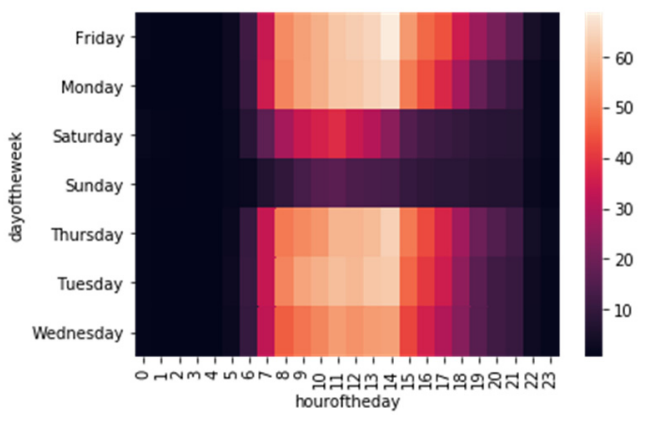

(b)

Figure A3. Heatmap of traffic at port gates. (a) Per month; (b) Per day of the week.

There were some interesting reflections to be extracted: January, May and September are the months with more traffic congestion, both in volume and in number high congested hours (till 5 p.m.). The central hours of the day are the ones in which the congestion is higher, especially between 12 and 2 p.m., where the maximum rates are noticed. Months with less traffic are April and November.

However, within the same day and within the week, the differences are notable. To focus on the scenarios of the experiment, it was interesting to include in this summary the usual "curves" of traffic evolution at gates of the port during each day of the week. Additionally, it was decided to leave the graphs separated for entries and exits. For the use-case in the experiment, those were put together to calculate the "traffic at the gate". 


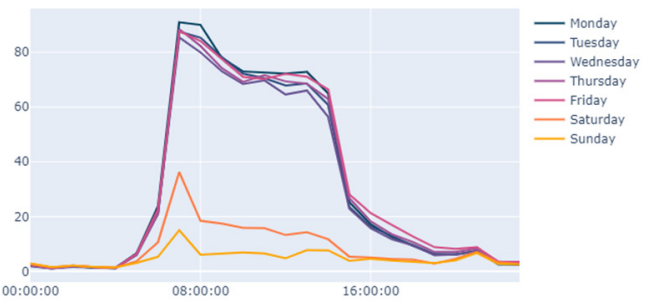

(a)

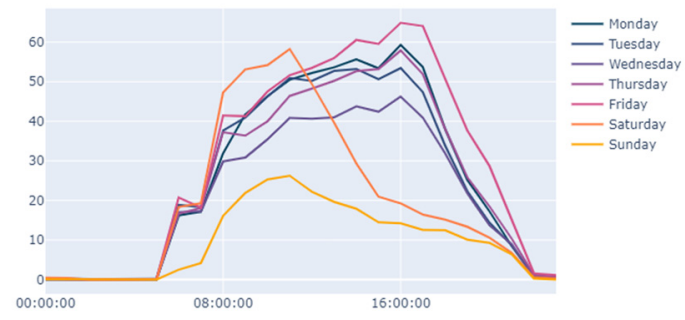

(c)

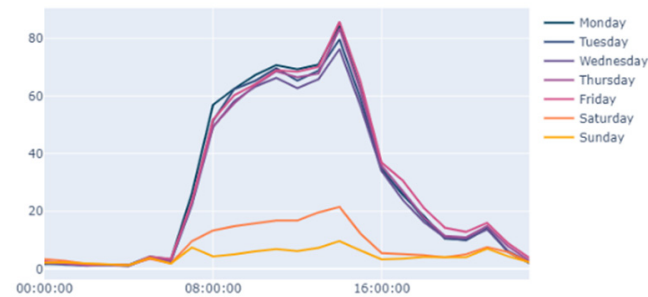

(b)

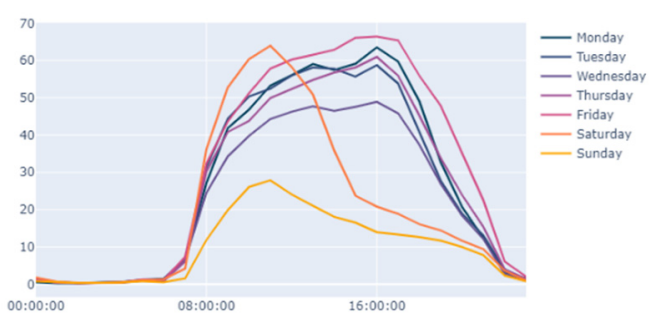

(d)

Figure A4. Average evolution of traffic in port gates, separated per direction. (a) Gate 10A-Entry; (b) Gate 10A-Exit. (c) Gate 16-Entry; (b) Gate 16-Exit.

Noticing the experiment scenarios, the evolution on days Tuesday, Thursday and Saturday was especially relevant to depict in this summary: Saturdays are not very congested with regards to traffic, logical as it is not a working day. However, more traffic is noticed on Saturdays for different reasons, such as some office works. Thursdays (with Fridays) are the days with more traffic, possibly due to the need to process the pending cargo/activities before finishing the week. For Tuesdays, it is observed that keep an almost identic distribution per hour considering the sum of the traffic of the two gates at both directions.

\section{Appendix C}

This appendix provides the screenshots of the results obtained for the nine scenarios defined in the experiment.
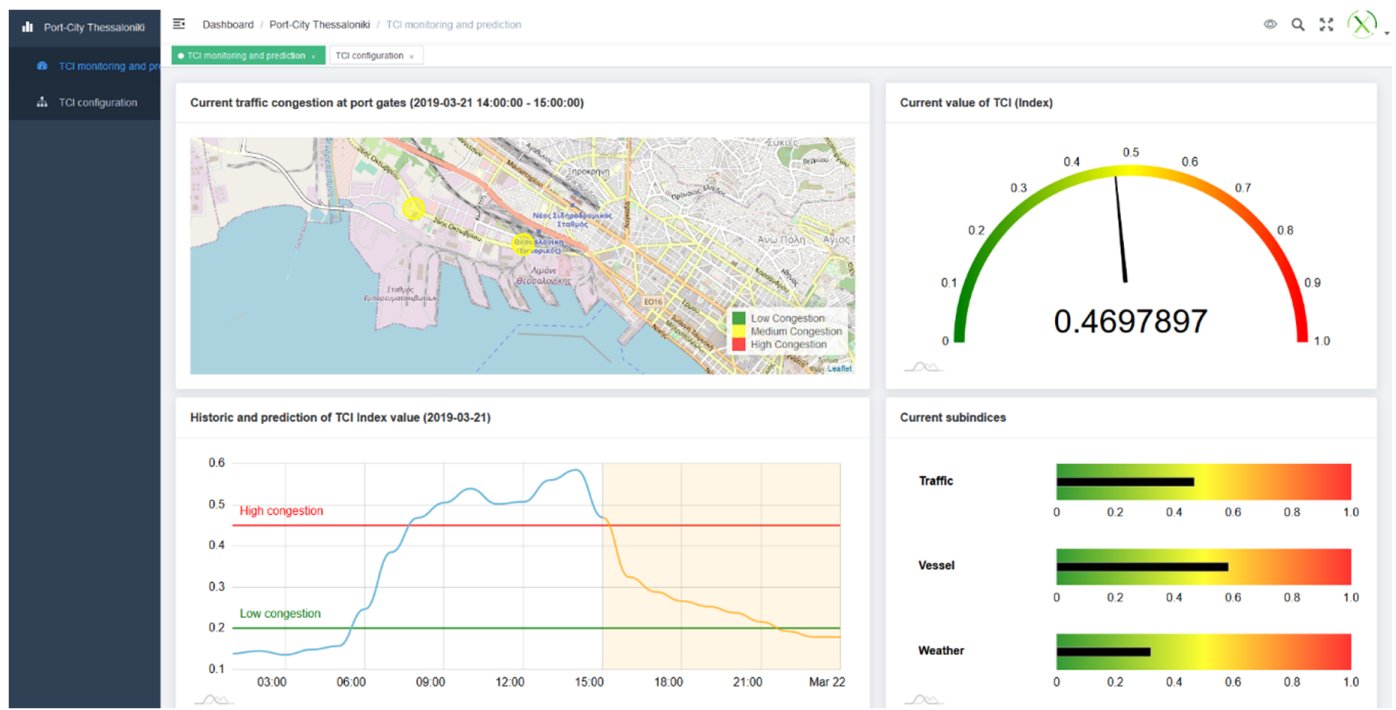

Figure A5. Visualization of the scenario 1.2 in the UI dashboard. 

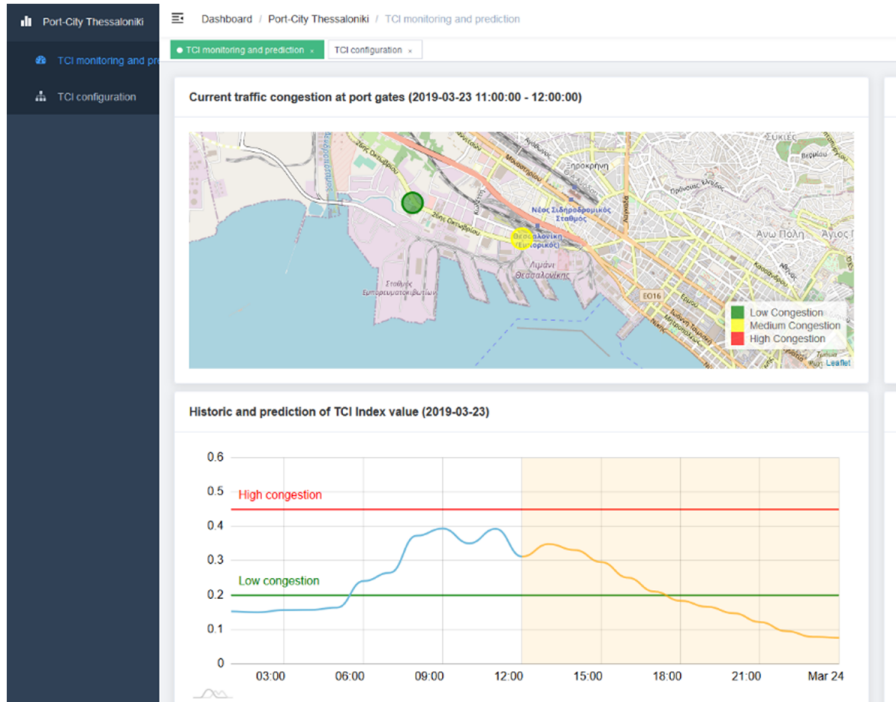

- $a \therefore \lambda)$.

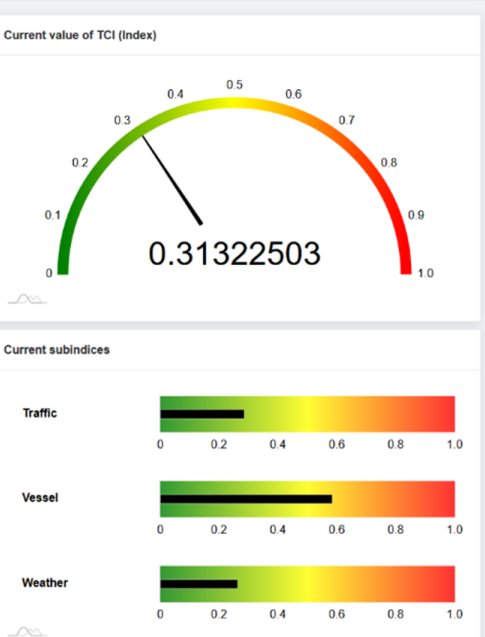

Figure A6. Visualization of the scenario 1.3 in the UI dashboard.
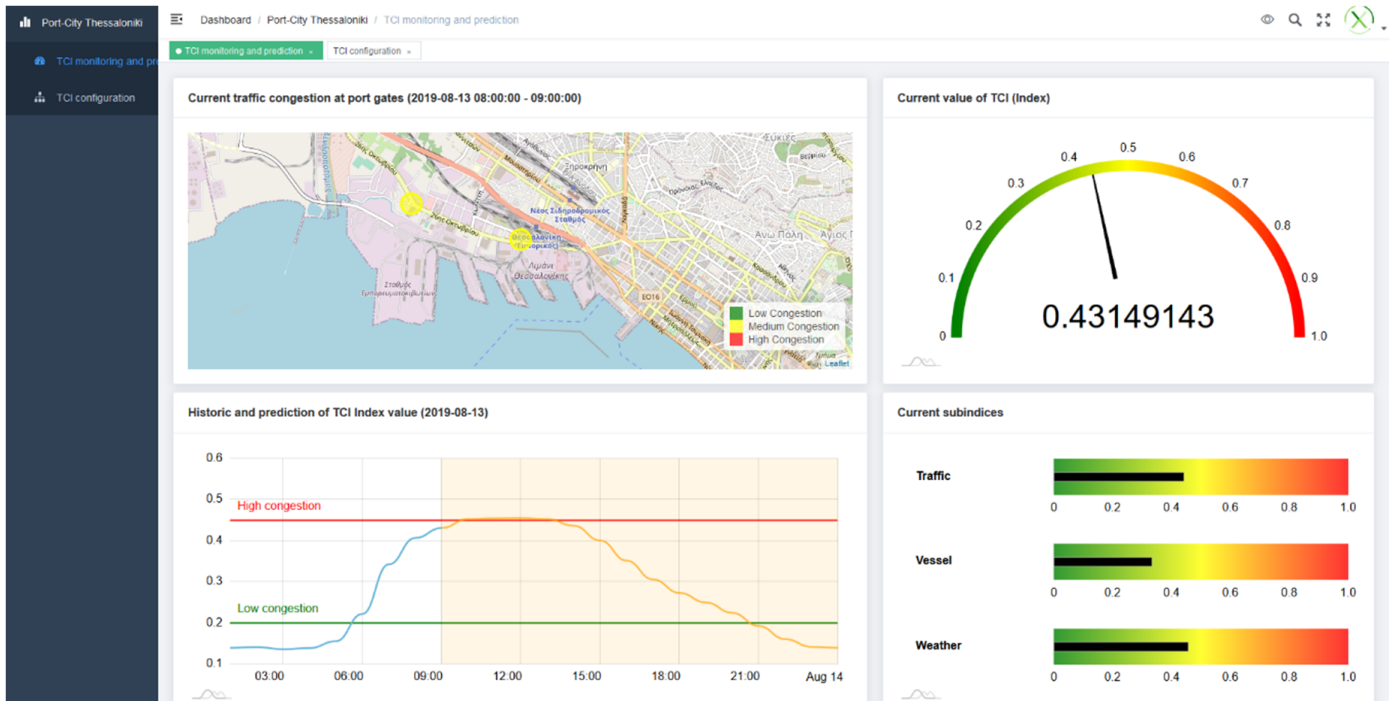

Figure A7. Visualization of the scenario 2.1 in the UI dashboard.
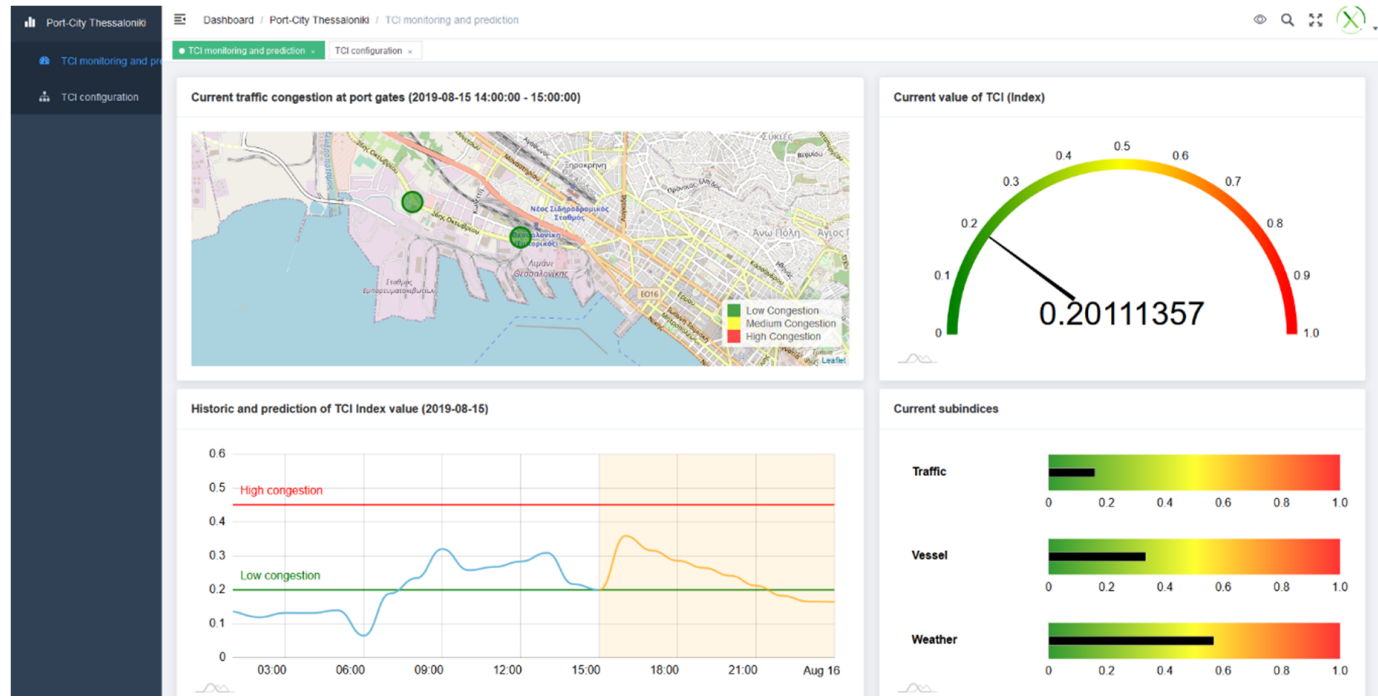

Figure A8. Visualization of the scenario 2.2 in the UI dashboard. 

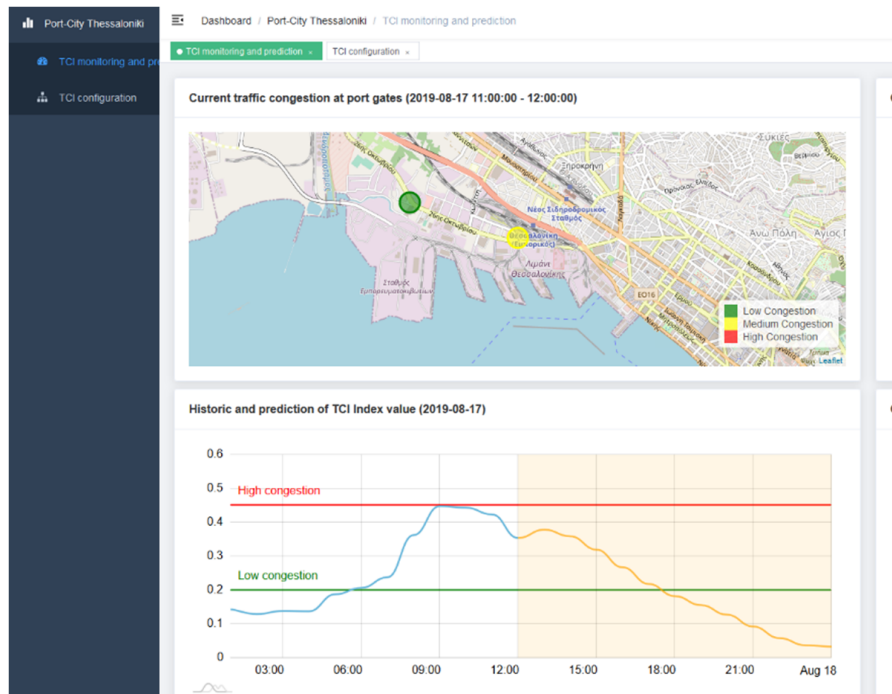

o a $\therefore(\lambda)$

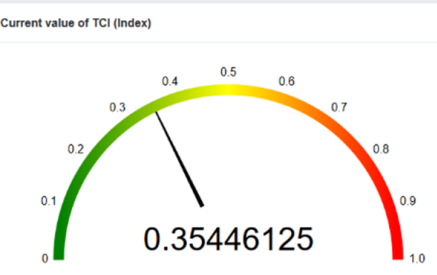

Figure A9. Visualization of the scenario 2.3 in the UI dashboard.
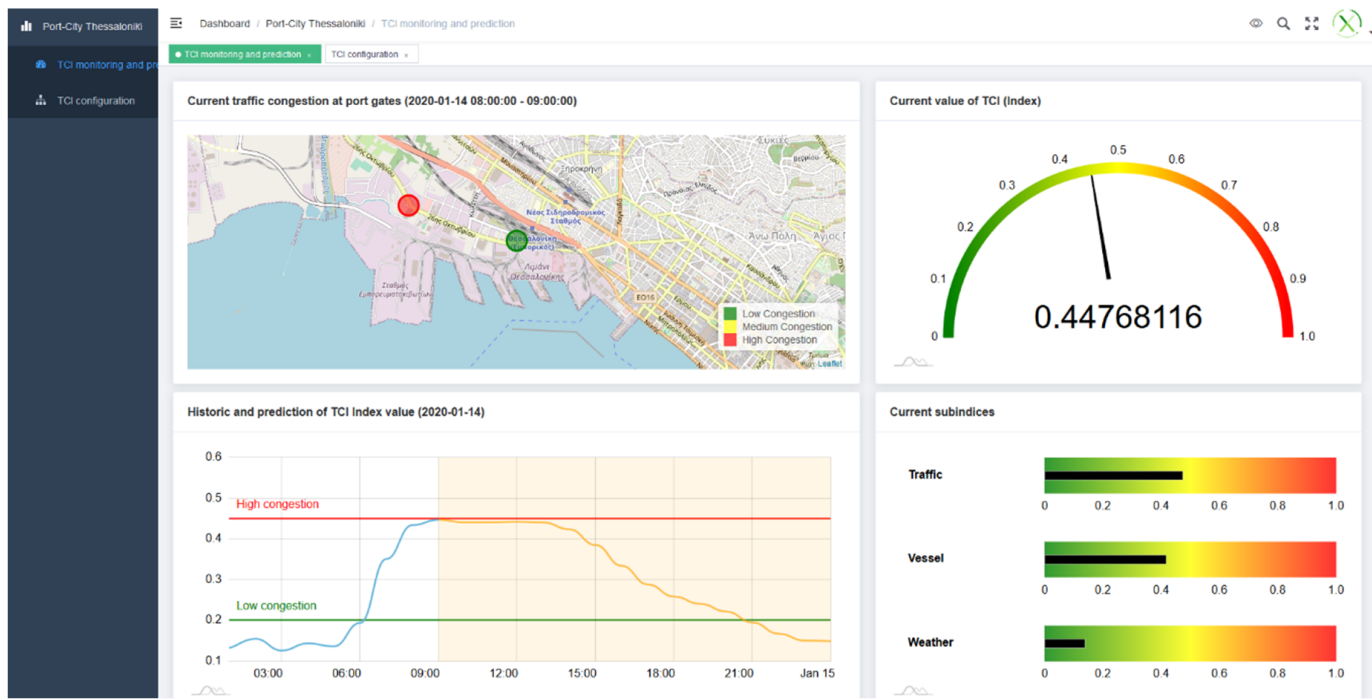

Figure A10. Visualization of the scenario 3.1 in the UI dashboard.
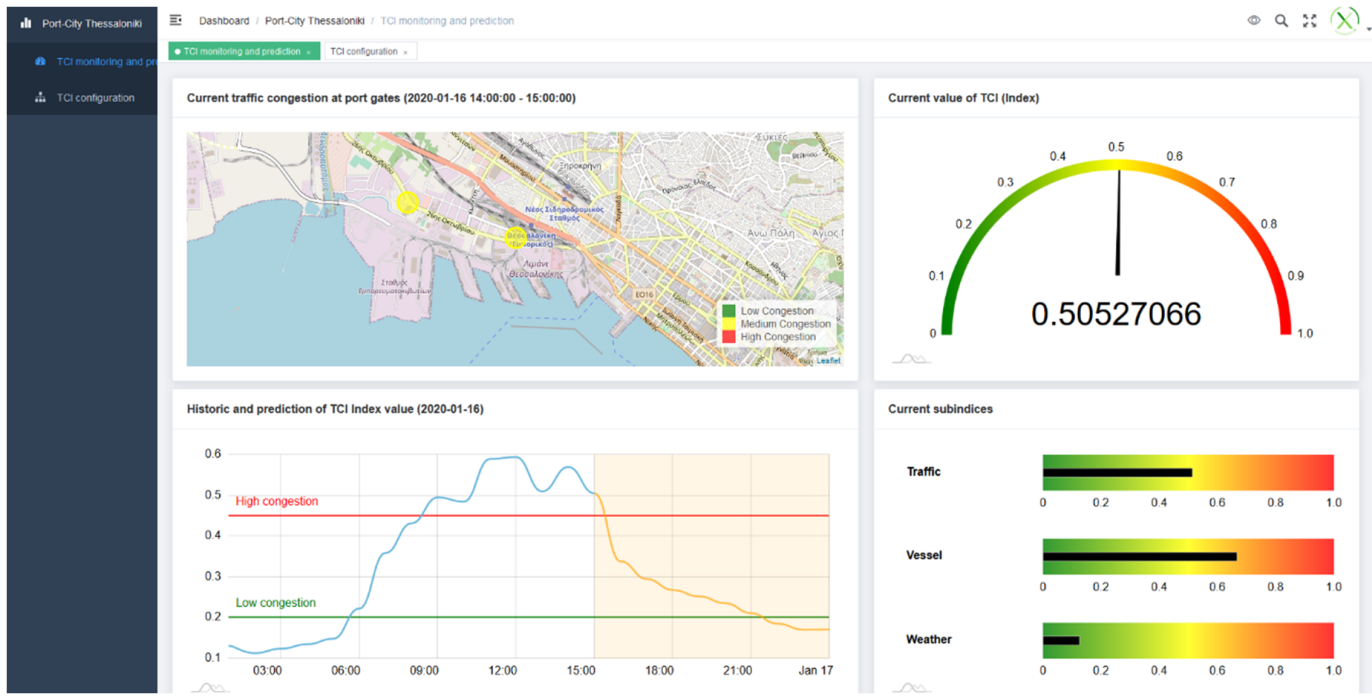

Figure A11. Visualization of the scenario 3.2 in the UI dashboard. 

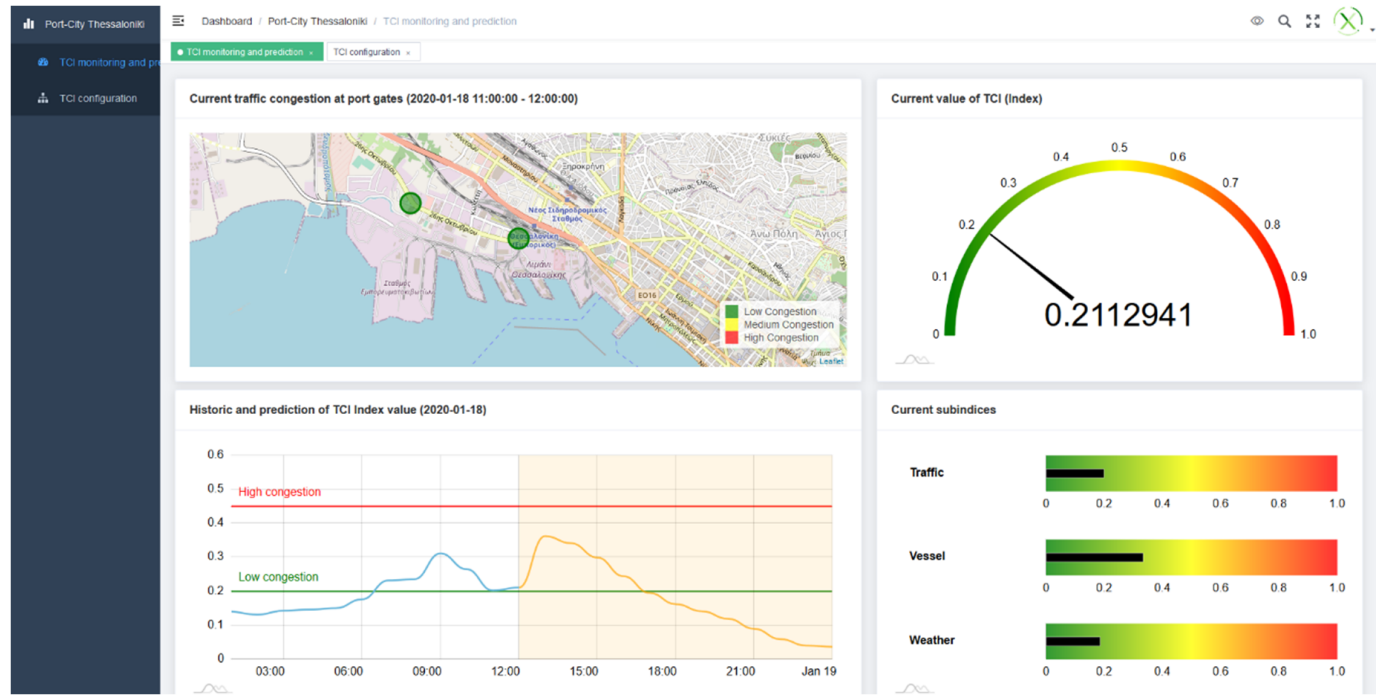

Figure A12. Visualization of the scenario 3.3 in the UI dashboard.

\section{References}

1. WHO. Urban Population Growth. Available online: https://www.who.int/gho/urban_health/situation_ trends/urban_population_growth_text/en/ (accessed on 29 June 2020).

2. United Nations Conference on Trade and Development. Review of Maritime Transport 2019; UN: New York, NY, USA, 2019; ISBN 978-92-1-112958-8.

3. Smart Port City. Available online: https://maritimestreet.fr/smart-port-city/ (accessed on 29 June 2020).

4. The World's 33 Megacities. Available online: https://www.msn.com/en-us/money/realestate/the-worlds-33megacities/ar-BBUaR3v (accessed on 29 June 2020).

5. DocksTheFuture Project Maritime Traffic Analysis and Forecast Review-Key Results. Available online: https:// www.docksthefuture.eu/wp-content/uploads/2020/04/Attachment_0-2019-09-09T135818.886-1.pdf (accessed on 29 June 2020).

6. Hamburg Port Authority: SmartPORT. Available online: https://www.hamburg-port-authority.de/en/hpa360/smartport/ (accessed on 29 June 2020).

7. Guo, H.; Wang, L.; Chen, F.; Liang, D. Scientific big data and digital earth. Chin. Sci. Bull. 2014, 59, 5066-5073. [CrossRef]

8. AIVP Agenda 2030 for Sustainable Port-Cities. Available online: https://www.aivpagenda2030.com/ (accessed on 29 June 2020).

9. Rodrigue, J.-P. Urban Transport Challenges. Available online: https://transportgeography.org/?page_id=4621 (accessed on 1 July 2020).

10. Passenger Cars in the EU. Available online: https://ec.europa.eu/eurostat/statistics-explained/index.php/ Passenger_cars_in_the_EU (accessed on 29 June 2020).

11. Average $\mathrm{CO}_{2}$ Emissions from New Cars and Vans Registered in Europe Increased in 2018, Requiring Significant Emission Reductions to Meet the 2020 Targets. Available online: https://ec.europa.eu/clima/news/averageco2-emissions-new-cars-and-vans-registered-europe-increased-2018-requiring-significant_en (accessed on 29 June 2020).

12. Perdiguero, J.; Jiménez González, J.L. Policy Options for the Promotion of Electric Vehicles: A Review; IREA-Working Papers; University of Barcelona, Research Institute of Applied Economics: Barcelona, Spain, 2012.

13. 7 Smart City Solutions to Reduce Traffic Congestion. Available online: https://www.geotab.com/blog/reducetraffic-congestion/ (accessed on 29 June 2020).

14. The Port and the City-Thoughts on the Relation between Cities and Ports. Available online: https: //theportandthecity.wordpress.com/ (accessed on 29 June 2020).

15. Yau, K.A.; Peng, S.; Qadir, J.; Low, Y.; Ling, M.H. Towards Smart Port Infrastructures: Enhancing Port Activities Using Information and Communications Technology. IEEE Access 2020, 8, 83387-83404. [CrossRef] 
16. Two Projects Led by Valenciaport Win the IAPH World Port Sustainability Awards 2020-Valenciaport. Available online: https://www.valenciaport.com/en/two-projects-led-by-valenciaport-win-the-iaph-worldport-sustainability-awards-2020/ (accessed on 29 June 2020).

17. Carpenter, A.; Lozano, R. European Port Cities in Transition; Springer: Berlin, Germany, 2020.

18. Science for Environment Policy. Indicators for Sustainable Cities. In-Depth Report 12; Produced for the European Commission DG Environment by the Science Communication Unit; UWE: Bristol, UK, 2018; ISBN 978-92-79-85127-8.

19. Frederiksen, P.; Barankova, Z.; Bauler, T.; Bell, S.; Cassar, L.; Conrad, E.; Eason, K.; Gudmundsson, H.; Sørensen, C.H.; Izakovicova, Z.; et al. POINT_Policy Influence of Indicators; European Commission: Bruxelles, Belgium, 2011; p. 8.

20. Saisana, M.; Tarantola, S.; Institute for the Protection and Security of the Citizen. Technological and Economic Risk Management Unit. In State-of-the-Art Report on Current Methodologies and Practices for Composite Indicator Development; European Commission, Joint Research Centre, Institute for the Protection and the Security of the Citizen, Technological and Economic Risk Management Unit: Ispra, Italy, 2002; Volume 214.

21. Mohammadi, A. Critical Infrastructure Management: Ports. In Proceedings of the Canadian Transportation Research Forum 53rd Annual Conference-The Future of Canada's Transportation System//L'avenir du Systéme de Transport du Canada, Gatineau, QC, Canada, 3-6 June 2018.

22. Ojo, A.; Curry, E.; Zeleti, F.A. A Tale of Open Data Innovations in Five Smart Cities. In Proceedings of the 2015 48th Hawaii International Conference on System Sciences, Kauai, HI, USA, 5-8 January 2015; pp. 2326-2335.

23. Ahlgren, B.; Hidell, M.; Ngai, E.C. Internet of Things for Smart Cities: Interoperability and Open Data. IEEE Internet Comput. 2016, 20, 52-56. [CrossRef]

24. Inkinen, T.; Helminen, R.; Saarikoski, J. Port Digitalization with Open Data: Challenges, Opportunities, and Integrations. J. Open Innov. Technol. Mark. Complex. 2019, 5, 30. [CrossRef]

25. Carrara, W.; Engbers, W.; Nieuwenhuis, M.; van Steenbergen, E. Analytical Report 4: Open Datain Cities. Available online: https://www.europeandataportal.eu/sites/default/files/edp_analytical_report_n4_-_open_ data_in_cities_v1.0_final.pdf (accessed on 29 June 2020).

26. Berends, J.; Carrara, W.; Vollers, H. Analytical Report 6: Open Datain Cities 2. Available online: https://www.europeandataportal.eu/sites/default/files/edp_analytical_report_n6_-_open_data_in_ cities_2_-_final-clean.pdf (accessed on 29 June 2020).

27. INTER-IoT Deliverables. Available online: https://inter-iot.eu/deliverables (accessed on 29 June 2020).

28. Activage Project D3.1 Report on IoT European Platforms. Available online: https://www.activageproject.eu/ docs/downloads/activage_public_deliverables/ACTIVAGE_D3.1_M3_ReportonIoTEuropeanPlatforms_V1. 0.pdf (accessed on 4 June 2020).

29. Mulero, R.; Almeida, A.; Azkune, G.; Mainetti, L.; Mighali, V.; Patrono, L.; Rametta, P.; Sergi, I. An AAL system based on IoT technologies and linked open data for elderly monitoring in smart cities. In Proceedings of the 2017 2nd International Multidisciplinary Conference on Computer and Energy Science (SpliTech), Split, Croatia, 12-14 July 2017; pp. 1-6.

30. Soldatos, J.; Kefalakis, N.; Hauswirth, M.; Serrano, M.; Calbimonte, J.-P.; Riahi, M.; Aberer, K.; Jayaraman, P.P.; Zaslavsky, A.; Žarko, I.P.; et al. OpenIoT: Open Source Internet-of-Things in the Cloud. In Interoperability and Open-Source Solutions for the Internet of Things; Podnar Žarko, I., Pripužić, K., Serrano, M., Eds.; Springer International Publishing: Cham, Switzerland, 2015; pp. 13-25.

31. The Open Source Platform for Our Smart Digital Future-FIWARE. Available online: https://www.fiware.org/ (accessed on 29 June 2020).

32. FIWARE Data Models. Available online: https://fiware-datamodels.readthedocs.io/en/latest/index.html (accessed on 29 June 2020).

33. Apache Kafka. Available online: https://kafka.apache.org/ (accessed on 29 June 2020).

34. FIWARE Orion Context Broker. Available online: https://fiware-orion.readthedocs.io/en/master/ (accessed on 29 June 2020).

35. Saborido, R.; Alba, E. Software systems from smart city vendors. Cities 2020, 101, 102690. [CrossRef]

36. Santana, E.F.Z.; Chaves, A.P.; Gerosa, M.A.; Kon, F.; Milojicic, D.S. Software Platforms for Smart Cities: Concepts, Requirements, Challenges, and a Unified Reference Architecture. ACM Comput. Surv. 2017, 50, 78. [CrossRef] 
37. Ramparany, F.; Marquez, F.G.; Soriano, J.; Elsaleh, T. Handling smart environment devices, data and services at the semantic level with the FI-WARE core platform. In Proceedings of the 2014 IEEE International Conference on Big Data (Big Data), Washington, DC, USA, 27-30 October 2014; pp. 14-20.

38. Smart Cities. Available online: https://www.fiware.org/community/smart-cities/ (accessed on 29 June 2020).

39. Araujo, V.; Mitra, K.; Saguna, S.; Åhlund, C. Performance evaluation of FIWARE: A cloud-based IoT platform for smart cities. J. Parallel Distrib. Comput. 2019, 132, 250-261. [CrossRef]

40. Ismagilova, E.; Hughes, L.; Dwivedi, Y.K.; Raman, K.R. Smart cities: Advances in research-An information systems perspective. Int. J. Inf. Manag. 2019, 47, 88-100. [CrossRef]

41. Albino, V.; Berardi, U.; Dangelico, R.M. Smart Cities: Definitions, Dimensions, Performance, and Initiatives. J. Urban Technol. 2015, 22, 3-21. [CrossRef]

42. Alavi, A.; Jiao, P.; Buttlar, W.; Lajnef, N. Internet of Things-Enabled Smart Cities: State-of-the-Art and Future Trends. Measurement 2018, 129, 589-606. [CrossRef]

43. Samih, H. Smart cities and internet of things. J. Inf. Technol. Case Appl. Res. 2019, 21, 3-12. [CrossRef]

44. Gea, T.; Paradells, J.; Lamarca, M.; Roldan, D. Smart cities as an application of internet of things: Experiences and lessons learnt in barcelona. In Proceedings of the 2013 Seventh International Conference on Innovative Mobile and Internet Services in Ubiquitous Computing, Taichung, Taiwan, 3-5 July 2013; pp. 552-557.

45. Lanza Calderón, J.; Sánchez González, L.; Gutiérrez Polidura, V.; Galache López, J.A.; Santana Martínez, J.R.; Sotres García, P.; Muñoz Gutiérrez, L. Smart city services over a future Internet platform based on Internet of Things and cloud: The smart parking case. Energies 2016, 9, 719. [CrossRef]

46. A Novel Architecture for Modelling, Virtualising and Managing the Energy Consumption of Household Appliances|AIM Project|FP7|CORDIS|European Commission. Available online: https://cordis.europa.eu/ project/id/224621 (accessed on 29 June 2020).

47. Intelligent Use of Buildings' Energy Information|IntUBE Project|FP7|CORDIS|European Commission. Available online: https://cordis.europa.eu/project/id/224286 (accessed on 29 June 2020).

48. Veronica, S.; Alberto, F.; Stefano, B. Internet of Things: Applications and challenges in smart cities. A case study of IBM smart city projects. Bus. Process Manag. J. 2016, 22, 357-367. [CrossRef]

49. Hao, L.; Lei, X.; Yan, Z.; ChunLi, Y. The application and implementation research of smart city in China. In Proceedings of the 2012 International Conference on System Science and Engineering (ICSSE), Dalian, China, 30 June-2 July 2012; pp. 288-292.

50. Ilin, I.; Jahn, C.; Weigell, J.; Kalyazina, S. Digital Technology Implementation for Smart City and Smart Port Cooperation. In Proceedings of the International Conference on Digital Technologies in Logistics and Infrastructure (ICDTLI 2019), St. Petersburg, Russia, 4-5 April 2019; Atlantis Press: St. Petersburg, Russia, 2019; pp. 493-496.

51. Molavi, A.; Lim, G.J.; Race, B. A Framework for Building a Smart Port and Smart Port Index. Int. J. Sustain. Transp. 2020, 14, 686-700. [CrossRef]

52. Moustaka, V.; Vakali, A.; Anthopoulos, L. A Systematic Review for Smart City Data Analytics. ACM Comput. Surv. 2018, 51, 1-41. [CrossRef]

53. Nardo, M.; Saisana, M.; Saltelli, A.; Tarantola, S. Tools for composite indicators building. European Commission Joint Research Centre. Inst. Prot. Secur. Citiz. Econom. Stat. Support Antifraud Unit I-21020 Ispra Italy Rep. Number EUR 2005, 21682, 140.

54. Saisana, M. Composite indicators: A review. In Proceedings of the Second Workshop on Composite Indicators of Country Performance, 26-27 February 2004; OECD: Paris, France, 2004.

55. Bandura, R. A Survey of Composite Indices Measuring Country Performance: 2008 Update; (UNDP/ODS Work. Pap.); United Nations Development Programme: Ney York, NY, USA, 2008; Volume 96.

56. Alam, M.; Dupras, J.; Messier, C. A framework towards a composite indicator for urban ecosystem services. Ecol. Indic. 2016, 60, 38-44. [CrossRef]

57. Amadi, M.; Cadbury, M.; Cisneros, C.E.; Coleman, C.; Freiche, D.-H.; Ganswindt, T.; Gutierrez-Campos, F.; Hands, G.; Harriss-Olson, M.; Kailis, G.M.; et al. 2001 Environmental Sustainability Index. In Proceedings of the An Initiative of the Global Leaders of Tomorrow Environment Task Force, World Economic Forum Annual Meeting 2001, Davos, Switzerland, 27 January 2001.

58. PIXEL Project D5.1 Environmental Factors and Mapping to Pilots. Available online: https://pixelports.eu/wp-content/uploads/2020/05/D5.1-Environmental-aspects-and-mapping-to-pilots.pdf (accessed on 29 June 2020). 
59. Tarantola, S.; Saisana, M.; Saltelli, A. Internal Market Index 2002: Technical Details of the Methodology; Inst. Prot. Secur. Citiz. Technol. Econ. Risk Manag. Unit I-21020 Ispra Italy; European Commission Joint Research Centre: Ispra, Italy, 2002.

60. Economic Sentiment Indicator-Eurostat. Available online: https://ec.europa.eu/eurostat/web/productsdatasets/product?code=teibs010 (accessed on 29 June 2020).

61. Human Development Index (HDI)|Human Development Reports. Available online: http://hdr.undp.org/en/ content/human-development-index-hdi (accessed on 29 June 2020).

62. Conceição, P. Human Development Report 2019. Beyond Income, beyond Averages, beyond Today: Inequalities in Human Development in the 21st Century; United Nations Development Programme: New York, NY, USA, 2019.

63. Fagerberg, J. Europe at the Crossroads: The Challenge from Innovation-Based Growth. In Centre for Technology, Innovation and Culture, University of Oslo, Working Papers on Innovation Studies; University of Oslo: Oslo, Norway, 2001; pp. 45-60, ISBN 978-0199241095.

64. COIN|Competence Centre on Composite Indicators and Scoreboards. Available online: https://compositeindicators.jrc.ec.europa.eu/ (accessed on 29 June 2020).

65. CITYkeys Project. Available online: http://www.citykeys-project.eu/citykeys/home (accessed on 29 June 2020).

66. Bosch, P.; Jongeneel, S.; Rovers, V.; Neumann, H.-M.; Airaksinen, M.; Huovila, A. CITYkeys D1-4 Indicators for Smart City Projects and Smart Cities. Available online: http://nws.eurocities.eu/MediaShell/media/ CITYkeysD14Indicatorsforsmartcityprojectsandsmartcities.pdf (accessed on 29 June 2020).

67. Make Healthy Choices Easier Options—Scientific American. Available online: https://www.scientificamerican. com/podcast/episode/make-healthy-choices-easier-options-12-09-20/ (accessed on 29 June 2020).

68. Airaksinen, M.; Pinto-Seppä, I.; Huovila, A.; Neumann, H.-M.; Iglar, B.; Bosch, P. Smart city performance measurement framework CITYkeys. In Proceedings of the 2017 International Conference on Engineering, Technology and Innovation, Madeira Island, Portugal, 27-29 June 2017; Mendonca, J.P., Jardim-Goncalves, R., Martins, J., Zarli, A., Marques, M., Pallot, M., Eds.; Wiley: Hoboken, NJ, USA, 2018; pp. 718-723.

69. FIWARE E Interoperabilidad Para Smart Cities. Available online: https://www.apegr.org/images/descargas/ J7OctESMARTCITY/2PresentacionFIWARE.pdf (accessed on 29 June 2020).

70. Chen, G.; Govindan, K.; Yang, Z. Managing truck arrivals with time windows to alleviate gate congestion at container terminals. Int. J. Prod. Econ. 2013, 141, 179-188. [CrossRef]

71. Patel, N.; Mukherjee, A.B. Assessment of network traffic congestion through Traffic Congestability Value (TCV): A new index. Bull. Geogr. Socio Econ. Ser. 2015, 30, 123-134. [CrossRef]

72. Aimsun Live: Model Every Movement at Every Moment. Available online: https://www.aimsun.com/ aimsun-live/ (accessed on 29 June 2020).

73. PTV Vissim: Traffic Simulation Software. Available online: https://www.ptvgroup.com/en/solutions/ products/ptv-vissim/ (accessed on 29 June 2020).

74. IBM Traffic Prediction Tool. Available online: https://researcher.watson.ibm.com/researcher/view_group_ subpage.php?id=1248 (accessed on 29 June 2020).

75. Veins: The Open Source Vehicular Network Simulation Framework. Available online: https://veins.car2x.org/ (accessed on 29 June 2020).

76. Mena-Yedra, R.; Gavaldà, R.; Casas, J. Adarules: Learning rules for real-time road-traffic prediction. Transp. Res. Procedia 2017, 27, 11-18. [CrossRef]

77. Karimpour, M.; Karimpour, A.; Kompany, K.; Karimpour, A. Online Traffic Prediction Using Time Series: A Case study. In Integral Methods in Science and Engineering, Volume 2: Practical Applications; Constanda, C., Dalla Riva, M., Lamberti, P.D., Musolino, P., Eds.; Springer International Publishing: Cham, Switzerland, 2017; pp. 147-156.

78. PIXEL Project. Available online: https://pixel-ports.eu (accessed on 29 June 2020).

79. Lacalle, I.; Llorente, M.Á.; Palau, C.E. Towards Environmental Impact Reduction Leveraging IoT Infrastructures: The PIXEL Approach. In Internet and Distributed Computing Systems; Montella, R., Ciaramella, A., Fortino, G., Guerrieri, A., Liotta, A., Eds.; Springer International Publishing: Cham, Switzerland, 2019; pp. 33-45.

80. Reference Architectural Model Industrie 4.0 (rami 4.0). Available online: https://www.plattform-i40.de/PI40/ Navigation/EN/Home/home.html (accessed on 29 June 2020). 
81. Industrial Internet Consourtium The Industrial Internet of Things. Volume G1: Reference Architecture; IIC PUB G1 V1. 80 20170131; Internet Consortium: Needham, MA, USA, 2017; Volume 58.

82. Sethi, P.; Sarangi, S.R. Internet of things: Architectures, protocols, and applications. J. Electr. Comput. Eng. 2017, 2017, 1-25. [CrossRef]

83. Containers \& Containerization-The Pros and Cons. Available online: https://spin.atomicobject.com/2019/ 05/24/containerization-pros-cons/ (accessed on 29 June 2020).

84. Pyngsi Framework. Available online: https://github.com/pixel-ports/pyngsi (accessed on 29 June 2020).

85. PIXEL Project D6.2 PIXEL Information System Architecture and Design-Version 2. Available online: https://pixel-ports.eu/wp-content/uploads/2020/05/D6.2-PIXEL-Information-System-architectureand-design-v2.pdf (accessed on 29 June 2020).

86. Apache Hive. Available online: https://hive.apache.org/ (accessed on 29 June 2020).

87. MySQL. Available online: https://www.mysql.com/ (accessed on 29 June 2020).

88. MariaDB Server. Available online: https://mariadb.org/ (accessed on 29 June 2020).

89. Elasticsearch. Available online: https://www.elastic.co/elasticsearch/ (accessed on 29 June 2020).

90. MongoDB. Available online: https://www.mongodb.com/ (accessed on 29 June 2020).

91. Node-RED. Available online: https://nodered.org/ (accessed on 29 June 2020).

92. Swarm Mode Overview | Docker Documentation. Available online: https://docs.docker.com/engine/swarm/ (accessed on 29 June 2020).

93. Kubernetes. Available online: https://kubernetes.io/ (accessed on 29 June 2020).

94. PIXEL Project D6.3 PIXEL Data Acquisition, Information Hub and Data Representation v1. Available online: https://pixel-ports.eu/wp-content/uploads/2020/05/D6.3_PIXEL-data-acquisition-information-huband-data-representation-v1.pdf (accessed on 29 June 2020).

95. Overview of Docker Compose|Docker Documentation. Available online: https://docs.docker.com/compose/ (accessed on 29 June 2020).

96. Kibana: Explore, Visualize, Discover Data. Available online: https://www.elastic.co/kibana (accessed on 29 June 2020).

97. Grafana: The Open Observability Platforms. Available online: https:/grafana.com/ (accessed on 29 June 2020).

98. Vue.js. Available online: https://vuejs.org/ (accessed on 29 June 2020).

99. PIXEL Project D5.2 PEI Definition and Algorithms v1. Available online: https://pixel-ports.eu/wp-content/ uploads/2020/05/D5.2-PEI-Definition-and-Algorithms-v1.pdf (accessed on 29 June 2020).

100. KeyPerformanceIndicator-FIWARE Data Models. Available online: https://fiware-datamodels.readthedocs. io/en/latest/KeyPerformanceIndicator/doc/spec/index.html (accessed on 29 June 2020).

101. What Is a Container?|App Containerization|Docker. Available online: https://www.docker.com/resources/ what-container (accessed on 29 June 2020).

102. Garcia-Alonso, L.; Moura, T.G.Z.; Roibas, D. The effect of weather conditions on port technical efficiency. Mar. Policy 2020, 113, 103816. [CrossRef]

103. Shang, P.; Li, R.; Liu, Z.; Li, X. Inclement weather impacts on urban traffic conditions. In Proceedings of the 15th COTA International Conference of Transportation Professionals Chinese Overseas Transportation Association (COTA) Beijing Jiaotong UniversityTransportation Research Board Institute of Transportation Engineers (ITE) American Society of Civil Engineers, Beijing, China, 24-27 July 2015; pp. 2213-2227.

104. Koźlak, A.; Wach, D. Causes of traffic congestion in urban areas. Case of Poland. In Proceedings of the SHS Web of Conferences, Samara, Russia, 26-27 November 2018; Volume 57, p. 1019.

105. TrafficThess-LIVE Traffic in Thessaloniki, Greece. Available online: https://www.trafficthess.imet.gr/ (accessed on 29 June 2020).

106. National Observatory of Athens-Meteo-Stations' Live Data and Database. Available online: http: //stratus.meteo.noa.gr/front (accessed on 29 June 2020).

107. How to Use Smart Data Models in Your Projects-FIWARE Data Models. Available online: https://fiwaredatamodels.readthedocs.io/en/latest/howto/index.html (accessed on 29 June 2020).

108. Gan, X.; Fernandez, I.C.; Guo, J.; Wilson, M.; Zhao, Y.; Zhou, B.; Wu, J. When to use what: Methods for weighting and aggregating sustainability indicators. Ecol. Indic. 2017, 81, 491-502. [CrossRef]

109. Wilson, M.C.; Wu, J. The problems of weak sustainability and associated indicators. Int. J. Sustain. Dev. World Ecol. 2017, 24, 44-51. [CrossRef] 
110. Kumar, S.V.; Vanajakshi, L. Short-term traffic flow prediction using seasonal ARIMA model with limited input data. Eur. Transp. Res. Rev. 2015, 7, 21. [CrossRef]

111. Prophet: Forecastig at Scale. Available online: https://facebook.github.io/prophet/ (accessed on 29 June 2020).

112. PIXEL Project D4.4 PredictiveAlgorithms v2. Available online: https://pixel-ports.eu/wp-content/uploads/ 2020/05/PIXEL_D4.4_Predictive-Algorithms_v2.0_Final.pdf (accessed on 29 June 2020).

113. Project Jupyter. Available online: https://jupyter.org/ (accessed on 29 June 2020).

114. FIWARE Cygnus. Available online: https://fiware-cygnus.readthedocs.io/en/latest/ (accessed on 29 June 2020).

115. NGSIElasticsearchSink-FIWARE Cygnus. Available online: https://fiware-cygnus.readthedocs.io/en/latest/ cygnus-ngsi/flume_extensions_catalogue/ngsi_elasticsearch_sink/index.html (accessed on 29 June 2020).

116. Node.js. Available online: https://nodejs.org/ (accessed on 29 June 2020).

117. Elasticsearch Node.js Client [7.x]. Available online: https:/www.elastic.co/guide/en/elasticsearch/client/ javascript-api/current/index.html (accessed on 29 June 2020).

118. Apache HTTP Server Project. Available online: https://httpd.apache.org/ (accessed on 29 June 2020).

119. Everything You Need to Know about Min-Max Normalization: A Python Tutorial. Available online: https://towardsdatascience.com/everything-you-need-to-know-about-min-max-normalization-inpython-b79592732b79 (accessed on 29 June 2020).

120. OpenStreetMap. Available online: https://www.openstreetmap.org/ (accessed on 29 June 2020).

121. Leaflet-A JavaScript Library for Interactive Maps. Available online: https://leafletjs.com/ (accessed on 29 June 2020).

122. AmCharts: JavaScript Charts \& Maps. Available online: https://www.amcharts.com/ (accessed on 29 June 2020).

123. FIWARE Catalogue. Available online: https://www.fiware.org/developers/catalogue/ (accessed on 29 June 2020).

124. Findlow, S. 'Citizenship' and 'Democracy Education': Identity politics or enlightened political participation? Br. J. Sociol. Educ. 2019, 40, 1004-1013. [CrossRef]

125. Mouradian, C.; Naboulsi, D.; Yangui, S.; Glitho, R.H.; Morrow, M.J.; Polakos, P.A. A comprehensive survey on fog computing: State-of-the-art and research challenges. IEEE Commun. Surv. Tutor. 2017, 20, 416-464. [CrossRef]

(C) 2020 by the authors. Licensee MDPI, Basel, Switzerland. This article is an open access article distributed under the terms and conditions of the Creative Commons Attribution (CC BY) license (http://creativecommons.org/licenses/by/4.0/). 